\title{
SALUD Y BUROCRACIA EN ESPAÑA. LOS CUERPOS DE SANIDAD NACIONAL (1855-1951)*
}

\author{
Jorge Molero Mesa (1) e Isabel Jiménez Wana (2)
}

(1) Departamento de Ciencias de la Documentación e Historia de la Ciencia. Facultad de Medicina. Universidad de Zaragoza. C/ Domingo Miral s/n. 50009-Zaragoza (España)

(2) Historia de la Ciencia. Facultad de Medicina. Universidad de Málaga.

${ }^{*}$ ) Este trabajo forma parte del Proyecto de Investigación PB94-0813-C03-03.

\section{DE LA PREOCUPACIÓN POR LO EXTERIOR A LA CONSIDERACIÓN DEL PELIGRO INTERNO. LOS MÉDICOS DE SANIDAD DEL ESTADO ENTRE 1855 Y 1918}

La Ley de Sanidad, promulgada el 28 de noviembre de 1855 , extendió el modelo napoleónico imperante en la Administración pública española al ámbito sanitario'. El centralismo político-administrativo en materia sanitaria quedaba garantizado por esta Ley que hizo recaer la Dirección General de Sanidad en el Ministerio de la Gobernación el cual quedó convertido en el vértice de una jerarquía burocrática que se continuaba con los Gobiernos civiles de todas las provincias del Estado y terminaba con los Directores especiales de Sanidad marítima, creados por esta Ley para impedir la entrada de «enfermedades pestilenciales exóticas» en España ${ }^{2}$. También a las órdenes de los Gobernadores civiles y para los asuntos de «Sanidad terrestre» la Ley seguía manteniendo a tres subdelegados de Sanidad por partido judicial (uno de medicina y cirugía, otro de farmacia y otro de veterinaria) que habían sido reglamentados en julio de 1848;

Correspondencia:

Departamento de Ciencias de la Documentación e

Historia de la Ciencia.

Facultad de Mcdicina.

Universidad de Zaragoza.

C/ Domingo Miral s/n.

50009-Zaragoza pero, a diferencia de los Directores de Sanidad marítima, este cargo era honorífico y no recibía retribución alguna. Ahora bien, tanto los Subdelegados como los Directores especiales de Sanidad Marítima eran nombrados por cargos políticos.

El Real Decreto de 17 de abril de 1867 fijó ciertas reglas para la provisión de las plazas en las Direcciones de Sanidad marítima con la intención de formar un «cuerpo perito» con derecho a «inamovilidad» pero al no aprobarse con posterioridad el reglamento correspondiente nunca pudo aplicarse dicho Decreto ${ }^{3}$. En consecuencia, la situación profesional de los médicos de Sanidad marítima se encontraba a merced de los continuos cambios de gobierno «... a las crisis y a los sacudimientos de la política ${ }^{4}$. De esta forma se resumía la situación de los directores de Sanidad marítima en 1874:

«[En España] se mudan de continuo estos funcionarios, quitándolos y poniéndolos caprichosamente, conforme las exigencias de los hombres políticos que ejercen influencia amistosa o que se hacen al contrario temer en las esferas de la gobernación del Estado. Basta que un diputado, un candidato ministerial lo exija, para que desaparezca el Director de un puerto y sea reemplazado por otro, ni más entendido en el ramo, ni adornado de mayor probidad profesional. Las plazas de médicos de baños y de Directores especiales de Sanidad maritima, son las destinadas a 
satisfacer las concupiscencias médico-políticas de la época, con grandísimo perjuicio de la naciónss.

En efecto, el «grandísimo perjuicio» no sólo provenía de la ignorancia de estos médicos en higiene y legislación sanitaria al no exigírseles prueba alguna de sus conocimientos para su contratación sino que, además, era «vergonzoso que estos facultativos pudieran aparecer ante los ojos de los capitanes de buques extranjeros y pasajeros distinguidos de otros países como ignorantes, incultos, mal educados o venales» ${ }^{5}$. Por tanto, junto con la petición realizada desde las revistas profesionales de que los cargos de directores de Sanidad marítima se proveyeran por oposición ${ }^{6-8}$ se reclamó que, además de los conocimientos especiales de Sanidad marítima, se les exigiera el conocimiento de idiomas porque «... tal medida contribuirá, no tan solo a garantizar un porvenir seguro, y un destino inamovible, sino también a estimular a los profesores al estudio de las lenguas vivas, colocándolos en aptitud de comprender autores modernos extranjeros que más se han distinguido en nuestro siglo, y elevando la clase médica a la altura que le corresponde ${ }^{4}$.

Sin embargo, antes de 1879 la preocupación gubernamental por constituir un cuerpo de funcionarios sanitarios fue mínima. En este año, Silvela, entonces Ministro de la Gobernación del Partido Conservador, pidió al Director General de Beneficencia y Sanidad que le propusiera lo necesario para organizar «la Sanidad terrestre y marítima» en un cuerpo especial que se denominaría de Sanidad civil, «sobre las bases de concursos y oposiciones para el ingreso en el cuerpo, que darán derecho a la inamovilidad a los funcionarios» ${ }^{9}$. No obstante, pasarían siete años hasta que, en 1886, con un Gobierno liberal, un Real Decreto crease el Cuerpo de Sanidad Marítima incluyendo en él a todos los empleados de las Direcciones de Sanidad marítima y de los lazaretos $^{10}$. La Sanidad terrestre quedó al margen de esta reforma; cuestión explicable pues, como ya hemos señalado, la mayor preocupación para el Estado en materia sanitaria era la entrada de «enfermedades pestilenciales exóticas» $y$, por tanto, al ser un territorio con un alto porcentaje de fronteras marítimas y colonias en ultramar, la base del sistema sanitario debía establecerse en el litoral.

\section{El Cuerpo de Sanidad Marítima}

No es casual que el primer Cuerpo de Sanidad se creara a finales del siglo XIX, en plena Restauración borbónica; pues se produjo dentro de un proceso general de normalización institucional auspiciado por el nuevo régimen con la finalidad de favorecer la estabilidad política. Entre los objetivos de dicho proyecto se encontraba acabar con el fenómeno de las cesantías y dar estabilidad a los cuerpos cspeciales de la Administración. Pero, no debemos limitarnos a la coyuntura restauracionista, pues también se estaba produciendo un proceso más amplio y complejo: la configuración del Estado liberal y la desaparición del Antiguo Régimen. En este sentido, para llevar a cabo el proceso de modernización ${ }^{11}$ del Estado se consideraron necesarias una serie de reformas administrativas, entre las que se encontraban «proporcionar estabilidad al colectivo de trabajadores por cuenta del Estado», y separar la Administración de la política ${ }^{12}$. Por tanto, desde esta perspectiva, había que modificar esa situación de constante movilidad y protagonismo de la política en las nuevas tareas que tendría que cumplir el Estado liberal, entre las que se encontraban las de carácter sanitario ${ }^{13}$. Por otra parte, la Revolución demográfica era entendida como uno de los indicadores de la modernización de una nación y el potencial demográfico condicionaba el poder de la misma en el ámbito mundial. En relación con esto, no es necesario, por ya bien conocido, señalar el impacto que tenían las epidemias. Y España, en las puertas del siglo $\mathrm{XX}$, seguía padeciendo importantes invasiones epidémicas. Quedaba claro, pues, cuales eran las preocupaciones y las prioridades del momento en materia sanitaria.

Por otra parte, las conclusiones de las distintas reuniones sanitarias internacionales ratificadas por España y las medidas tomadas en cada caso de brote epidémico habían generado un cúmulo de legislación tal que, según reconocía el preámbulo del Real Decreto de 1886 , no solo no garantizaba la salud pública sino que además ocasionaba «... a veces perjuicios $y$ 
vejámenes al comercio en desprestigio de nuestro prudente y racional sistema de defensa contra la importación de contagios", todo ello unido al estado lamentable de las instalaciones, a la falta de disciplina en los lazaretos sucios, y a la «constante movilidad y falta de aptitud del personal», hacía imprescindible la reforma ${ }^{14}$, en tanto que había que adaptarse a los principios de modernidad administrativa: inamovilidad, especialización y tecnocratización.

En esta línea, se dividieron las Direcciones de Sanidad de los puertos y lazaretos en cuatro clases y se disponía que los dircctores y secretarios de los de primera, segunda, tercera así como los directores de cuarta, fuesen médicos y los secretarios de las Direcciones de cuarta, médicos o farmacéuticos. Tanto a los directores como a los médicos de visita de naves y a los secretarios se les exigía que hablasen francés «como idioma más generalizado». Además, solamente se ingresaría en el Cuerpo «probando la suficiencia mediante ejercicios» y la separación del mismo sólo se efectuaría «mediante la instrucción del oportuno expediente». Sin embargo, el respeto a los «derechos adquiridos» quedaba asegurado en las disposiciones transitorias al posibilitar la permanencia en el Cuerpo sin opositar a aquellos médicos con más de ocho años en Sanidad marítima y con conocimientos de francés. Por otra parte, la oferta de entrada en el Cuerpo a otros profesionales con conocimientos de higiene y Sanidad marítima sin necesidad de opositar era muy amplia. Para poder participar en los ejercicios de ingreso al Cuerpo facultativo era necesario llevar cinco años de antigüedad en la profesión probados con la fecha del título.

La plantilla de las Direcciones de Sanidad Marítima, aprobada junto al Real Decreto que creaba el Cuerpo de Sanidad Marítima, comprendía 98 Directores médicos de visita de naves, 35 Secretarios médicos, 3 médicos de bahía y 3 médicos de consigna, por último 48 médicos suplentes. El proceso de jerarquización en el ámbito del funcionariado sanitario, culminó un año después con la aprobación del Reglamento Orgánico provisional de la Sanidad marítima, en cuyo artículo 58 se consignaba la formación de un «escalafón especial de estos médicos por orden de rigurosa antiguie- dad en el ramo» ${ }^{15}$. Se establecía así, lo que autores como Villacorta Baños consideran «un tipo de organización burocrática de caráctcr privilegiado con relación al régimen general administrativo», entre cuyas particularidades se encuentran: una estructura escalafonada, con condiciones de ascenso «más impermeable a la interferencia política» ${ }^{16}$.

En la última década del siglo XIX, cambios en el ámbito de la medicina en relación con la explicación causal de las enfermedades infectocontagiosas, y cambios económicos, sociales y políticos en el ámbito nacional, fueron coetáneos a una modificación en las prioridades establecidas por la Sanidad nacional. En efecto, las plantillas de Sanidad Marítima se fueron acomodando a los presupuestos tanto como a las necesidades epidemiológicas, siguiendo la concepción liberal decimonónica del Estado «guardián». Si en los años 80 dichos presupuestos fueron generosos para los asuntos sanitarios debido a la presencia del cólera, en los 90 se vieron reducidos a la mitad y con ellos el número de médicos y el gasto en material sanitario de las estaciones marítimas $^{17}$. La respuesta por parte del gobierno a las quejas de los Directores de cuarta clase que solicitaban un aumento de su «homeopática paga» ${ }^{18}$ fue la reorganización de plantillas que imponía la Ley de presupuestos de 1892 con el fin de «obtener economías» ${ }^{19}$. El recorte afectó fundamentalmente a las Direcciones de tercera y cuarta clase que quedaron reducidas a 4 y 37 respectivamente. También se suprimieron los secretarios en todas las Direcciones de cuarta clase menos en Ceuta, Garrucha y Mahón. En relación con las plantillas originales de 1886 desaparecieron un total de 46 plazas ocupadas por empleados facultativos, de las cuales 35 correspondían a Directores médicos de bahía antes Director médico de visita de naves. Asimismo se aumentó el sueldo a los Directores médicos de los puertos de primera clase.

Todas estas medidas, que sin duda iacidirían en un aumento de la jerarquización del Cuerpo de Sanidad Marítima, coincidieron con la creación de plazas de Inspectores Provinciales de Sanidad como más adelante veremos. A partir de aquí, el auge de la Sanidad interior frente a la exterior fue implantándose paulatinamente. 
En 1899, Carlos $\mathrm{M}^{\mathrm{a}}$ Cortezo (1850-1933) fue nombrado Director General de Sanidad -organismo restablecido a la par- con categoría de Jefe Superior de Administración civil, es decir la máxima categoría a la que un funcionario podía aspirar ${ }^{20}$. Bajo su mandato se reformó el esquema de la Administración sanitaria civil que quedó constituida en dos secciones denominadas de Sanidad exterior y de Sanidad interior. Esta división quedó establecida a la par que se reglamentaba la Sanidad exterior y se creaba un nuevo Cuerpo con esta denominación ${ }^{21}$. El nuevo Cuerpo de Sanidad exterior incorporó, en su sección tercera, a los empleados del extinto Cuerpo de Sanidad Marítima y absorbió a los empleados técnicos pertenecientes a la Secretaría del Real Consejo de Sanidad que formaron la sección primera. Otras dos secciones se crearon aun sin tener las plantillas aprobadas: la segunda que comprendería en su momento al Jefe y los empleados técnicos de la Sección de Sanidad exterior de la Dirección General de Sanidad y la cuarta que se formaría con los empleados con funciones sanitarias permanentes en las fronteras.

La inexistencia de personal fijo en las fronteras con Francia y Portugal se suplía nombrando comisiones de Inspección con miembros de la Secretaría del Real Consejo de Sanidad cuando un peligro epidémico surgía en uno de esos países. De esta forma, en agosto de ese mismo año se nombró una Comisión con motivo de la epidemia de peste desatada en Oporto y disuelta cuando aquella remitió en diciembre. Formaban parte de esta Comisión Bernabé Malo de Poveda (1844-1926), nombrado para establecer la Inspección sanitaria de Túy, Amalio Gimeno (1851-1936) y Angel Pulido (1853-1932), estos últimos como Inspectores generales ${ }^{22}$.

Una de las reformas más significativas que introdujo este Reglamento fue la derogación del régimen cuarentenario establecido para la Sanidad marítima por la Ley de Sanidad de 1855 . En el artículo $9^{\circ}$ atribuía a la Dirección General de Sanidad la capacidad de «fiscalizar por medio de las Inspecciones que considere precisas los lazaretos, estaciones sanitarias y laboratorios, girándose al efecto visitas periódicas en tiempos normales y visi- tas extraordinarias en los de epidemia o peligro de ella». La adopción de un sistema de inspección médica implicó un cambio estructural en la organización sanitaria marítima que conllevaría una reducción drástica en el número de empleados facultativos en los puertos habilitados para el comercio. La reforma consistió en dividir las costas españolas en Distritos sanitarios. En cada uno de ellos existiría una Estación sanitaria de primera clase y varias de segunda así como un número determinado de Inspecciones locales en los distintos puertos habilitados ${ }^{23}$. El personal médico quedó reducido a un Director en las estaciones sanitarias de primera y segunda clase y limitados a las estaciones de primera clase- $-\mathbf{a}$ los médicos de bahía que se considerasen necesarios. Por su parte, en todos los puertos abiertos al comercio debía haber uno o más médicos habilitados -es decir no pertenecientes al Cuerpo de Sanidad exterior- que ocuparían las inspecciones locales. Estos últimos serían nombrados a propuesta de los Gobernadores civiles y su remuneración se produciría a través de emolumentos procedentes de las tarifas y derechos sanitarios que debían hacer efectivos los capitanes de los buques que arribaran en el puerto. Las plantillas que se configuraron con esta nueva estructura sanitaria sólo podían incluir a poco más de 40 facultativos entre Directores de estaciones sanitarias y médicos de bahía.

A pesar de todas las reformas descritas, la Sanidad exterior estaba en 1902 todavía mal organizada y poseía unos servicios deficientes, tal y como reconoció el Director General de Sanidad, Angel Pulido en ese año ${ }^{17}$. En 1901 todavía no se habían podido crear las secciones segunda y cuarta porque aun no había personal para formarla, motivo por el cual se publicaron los escalafones de la primera y tercera sección sin más demora ${ }^{24}$. Dos años después el escalafón de médicos en activo de la tercera sección comprendía a 44 funcionarios y el número de excedentes sc clcvaba a 87 como producto de las sucesivas amortizaciones de plazas $^{25}$. Por su parte, la flamante Instrucción General de Sanidad promulgada de forma definitiva en 1904 se limitó a confirmar, dentro del Capítulo XI, el Reglamento de Sanidad exterior de 1899 además de adjudicar a la recién 
creada Inspección General de Sanidad exterior las funciones de la Higiene del transporte por ferrocarril ${ }^{26}$.

Las plantillas del Cuerpo de Sanidad exterior continuaron a lo largo del primer tercio del siglo XX acoplándose a las necesidades epidemiológicas, a las normas internacionales suscritas por España y a los presupuestos estatales. En este caso, con motivo de los acuerdos de la Conferencia Internacional de París de 1903, se volvió a reformar la Sanidad exterior pero en esta ocasión dicho acuerdos exigían que la reforma se hiciera «en armonía con los conocimientos bacteriológicos y epidemiológicos modernos ${ }^{27}$ lo que redundaría en una «más amplia libertad para el comercio y en las menores restricciones sanitarias posibles» ${ }^{28}$. Seis años más tarde, en 1909, se promulgó un nuevo Reglamento provisional de Sanidad exterior $^{29}$ que pudo ser desarrollado gracias a un crédito extraordinario para atenciones sanitarias de dos millones de pesetas que se libraron con motivo de la epidemia colérica que amenazaba desde Rusia ${ }^{30}$. Una de las novedades aportadas por este Reglamento fue la creación de las esperadas Inspecciones sanitarias a lo largo de las fronteras con Francia y Portugal con personal permanente. Las Inspecciones de primera categoría se dotaron con un Inspector facultativo y uno o varios Subinspectores médicos y las de segunda sólo con un Subinspector médico ${ }^{29}$ pero las plantillas no se aprobarán hasta el presupuesto de $1913^{31}$.

La Sanidad marítima se reorganizó bajo las directrices acordadas en París con la fórmula impuesta de «personal apto y material apropiado» para hacer frente a los nuevos procedimientos del régimen sanitario. Hasta la fecha, los funcionarios médicos ingresaban en el Cuerpo tras aprobar un examen cuyos contenidos no se habían modificado desde el Reglamento de 1877 . El temario no sólo adolecía de una falta completa de referencias a las doctrinas bacteriológicas sino que mantenía vigentes los conceptos de «miasma» y «efluvio», amén de incluir un tema completo dedicado a la exposición de las doctrinas contagionista y anticontagionista ${ }^{32}$. La primera medida fue obligar a estos empleados a que hicieran, por tandas, prácticas de bacteriología en el Instituto Nacional de Higiene Alfonso XIII. Consecuentemente se les aumentó el sueldo pues, tal como reconocía la propia Administración «... al que mal se le paga no hay derecho a exigirle grandes esfuerzos en el cumplimiento del deber ${ }^{29}$. Al mismo tiempo se ampliaron las plantillas de personal entre los que se encontraban doce Directores médicos y tres médicos segundos ${ }^{29}$. En enero de 1911 se publicó el nuevo escalafón unificado de Sanidad exterior tal y como exigía el Reglamento al suprimir las secciones del mismo.

En cuanto a los lazaretos el convenio de París de 1903 dispuso la obligación para España de disponer de un lazareto cuarentenario para cada uno de sus mares dotados de laboratorio con personal especializado. Se reformaron «los casi abandonados» lazaretos de San Simón (Vigo) para el Atlántico y de Mahón para el Mediterráneo ${ }^{29}$ y se autorizó a las Hermanas de la Caridad para cuidar de los enfermos del mismo.

Esta reforma fuc el inicio del definitivo declive de la Sanidad exterior potenciado por el gobierno liberal que no asumió en su totalidad el Reglamento provisional de 1909 promulgado por los conservadores. Un crédito de quinientas mil pesetas concedido por Real Decreto de 9/9/1910 para construir de nueva planta las Estaciones sanitarias terrestres de segunda categoría no se llegó a invertir en este menester por «no arriesgarse el Estado a hacer el sacrificio de la instalación permanente de unas estaciones sanitarias de dudoso éxito profiláctico ${ }^{28}$. Otro crédito extraordinario de un millón de pesetas librado por Real Decreto de 16/8/1911 se invirtió en mejorar la Sanidad interior a través de la adquisición de laboratorios de investigación bacteriológica «para el rápido diagnóstico de los enfermos», aparatos de esterilización de agua y en «barracas Doecker» de alojamiento para enfermos o sospechosos de cólera. En definitiva, tal y como se reconocía en la memoria escrita por el gobierno liberal para justificar su actuación sanitaria «el ideal de la profilaxis contra las epidemias, puede decirse que estriba en el perfeccionamiento de la Sanidad interior más que de la exterior» ${ }^{28}$. 
Consecuentemente, la renovación del personal de Sanidad exterior se inició de forma efectiva en 1910 con la expulsión del Cuerpo de los empleados que no acreditasen su edad en el plazo establecido lo que afectó fundamentalmente al personal excedente que en su mayoría no respondió a esta petición $^{33}$. El personal en activo se caracterizaba precisamente por su elevada edad como se puede comprobar en el escalafón de 1911 una vez incorporado este dato. La edad media de los 57 médicos en activo era de 59 años y los dos más jóvenes tenía 49 años cada uno ${ }^{34}$. Por esto no es extrañar que los ocho médicos que ingresaron en el Cuerpo en 1912 tuvieran todos una edad menor de 31 años a pesar de no exigirse en la convocatoria límite de edad alguno. Un año después, un concurso interno para la provisión de dos plazas de bacteriólogos en las estaciones sanitarias de Vigo y Mahón restringió la convocatoria a esos mismos médicos recién ingresados. Según el preámbulo de la Real Orden -que no respetó los artículos que regulaban los concursos del Reglamento provisional de Sanidad exterior de 1909«los antiguos miembros del Cuerpo no estaban capacitados para desempeñar estos puestos» al no haber estado «obligados a demostrar conocimientos especiales en Bacteriología, materia incluida por primera vez y con la extensión que las modernas teorías profilácticas que la ciencia aconseja fueron incluidas en los ejercicios teóricos y prácticos a que se sujetaron estas últimas oposiciones» ${ }^{35}$. Para reforzar la renovación del personal técnico en Sanidad exterior se rebajó a 35 años la edad máxima para poder participar en las siguientes oposiciones convocadas en octubre de $1913^{36}$.

Este proceso de renovación no estuvo exento de tensiones entre los miembros de la Sanidad exterior. Según reconoció posteriormente uno de los recién ingresados en el Cuerpo, a partir de estas oposiciones se estableció entre viejos y jóvenes «un dañoso antagonismo... comenzando una lucha impertinente para que fueran cuanto antes eliminados todos aquellos funcionarios que ingresaron en el Cuerpo con anterioridad a nosotros» ${ }^{27}$.

\section{La Sanidad interior}

La Ley de Sanidad de 1855 sustituyó el sistema cuarentenario interior por otro basado en la inspección médica «para los casos inminentes de epidemia o contagio». En estos casos, el Gobierno, a propuesta del Consejo de Sanidad podía nombrar «delegados facultativos» para que realizaran visitas de inspección «allí donde el bien público lo exija». En tiempos de calma epidémica, la vigilancia estaba en manos de los subdelegados de Sanidad de medicina y cirugía los cuales estaban obligados por su Reglamento de 1848 a «presentar a los Jefes políticos [Gobernadores civiles] y a los alcaldes cuantas reclamaciones creyeren necesarias por las faltas o contravenciones... en la observancia de los principios generales de la higiene pública». También debían dar cuenta a los Gobernadores civiles de las «enfermedades epidémicas que apareciesen en sus respectivos distritos» ${ }^{37}$. No obstante, la labor de los subdelegados en este terreno fue siempre criticada pues, al parecer, en la práctica no ejercían su labor de inspección sanitaria. En 1902, el Director General de Sanidad, Angel Pulido, reconocía la ineficacia de esta institución. Según su experiencia «... los llamamos y no nos respondieron, esperamos sus estudios y no llegaron, anhelamos su celo y nos faltó casi siempre, inquirimos sus iniciativas y no las hemos encontrado* ${ }^{17}$.

No obstante, y a pesar de la inoperancia de los subdelegados de Sanidad, la primera figura sanitaria que llegaría a encargarse en exclusividad de vigilar la salud colectiva no fue creada hasta el verano de 1892. En efecto, con motivo de la epidemia de cólera que se estaba desarrollando en Europa en ese año (Hamburgo, Altona, Bélgica, Francia e Imperio Ruso) y coincidiendo con la reducción de la plantilla del personal de la Sanidad marítima, una Real Orden de 29 de agosto creó el cargo de Inspector provincial de Sanidad ${ }^{38}$. Su nombramiento correspondía a los Gobernadores civiles y estos debían elegir en primer lugar a los médicos que ya ocupaban el puesto de Subdelegado de medicina. Según esta Real Orden los Inspectores provinciales debían estar en comunicación con los subdelegados de su provincia - ahora convertidos en Inspectores de distri- 
to- $y$ estos con los médicos titulares. Entre las funciones de los Inspectores provinciales se encontraba «proponer a las autoridades las medidas que estimen oportunas sobre el régimen higiénico y sanitario, hacer pedidos de materias desinfectantes y cuidar de que sean útilmente aprovechadas». Además, los Inspectores provinciales sólo serían remunerados en caso de epidemia y a cargo de los créditos extraordinarios librados para el caso. Un año después, se regularon estas cantidades de dinero y se estipuló que los Inspectores provinciales debían ejercer su profesión en la capital de la provincia $^{39}$. Todo ello a pesar de que, con frecuencia, su misión les ocasionara gastos considerables, según afirmaba Angel Pulido en $1902^{17}$.

La Instrucción General de Sanidad, aprobada provisionalmente en julio de $1903^{40}$, suprimió la Dirección General de Sanidad y creó dos Inspecciones Generales una de Sanidad interior y otra de Sanidad exterior. Este cambio obedecía a la voluntad de los gobernantes, al menos sobre el papel, de hacer «independiente la Sanidad de la política, el funcionario de la Sanidad del burócrata gubernativo ${ }^{41}$. Los responsables de dichas inspecciones, según el artículo 34 de la Instrucción, serían nombrados por concurso entre doctores en medicina con más de diez años de ejercicio de la profesión y se atendería como condiciones preferentes: «ser académico de la Real Academia, ser o haber sido consejero de Sanidad, ser o haber sido catedrático de medicina o haber servido en la administración sanitaria en cargos superiores a Jefe de la tercera clase o haber hecho publicaciones relativas a sanidad o higiene». Tras ocuparse los cargos por Eloy Bejarano Sánchez (1855-1917) (interior) y por Manuel Alonso Sañudo (18561912) (exterior), un Real Decreto de julio de 1904 aclaraba que las facultades conferidas a los Inspectores generales, una vez suprimida la Dirección General de Sanidad, estarían limitadas al carácter propio de Jefes de Sección y a su categoría de Jefes de Administración de primera clasc.

Al mismo tiempo, la Instrucción configuró un Cuerpo funcionarial de Inspectores Provinciales de Sanidad dependientes de la Ins- pección General de Sanidad interior. En el artículo 48 se dispuso que los Inspectores provinciales debían ocupar su cargo tan sólo por oposición pública directa. Para ello debían poseer el título de doctor en Medicina y Cirugía y contar con más de ocho años de ejercicio profesional. La figura de Inspector provincial se dotó con autoridad sanitaria al señalarse en el artículo 47 de la Instrucción que se comunicaría directamente con los Inspectores generales y acudiera al Gobernador civil sólo en los casos en los que su propia autoridad fuese desatendida o insuficiente.

La Instrucción, en su artículo 39, encomendaba al Inspector provincial la organización y registro de la higiene de las prostitutas, su hospitalización o tratamiento domiciliario. Por este motivo, en el artículo 50 se contemplaba la posibilidad de que los médicos higienistas encargados de esta tarea optaran por concurso al cargo de Inspector provincial antes de efectuarse las primeras oposiciones. El higienista debía haber obtenido su cargo por oposición y demostrar que en dichas oposiciones se les exigió la suficiencia en Higiene y Administración sanitaria. Por otra parte, el único privilegio que recogía la Instrucción para con aquellos médicos que habían ejercido hasta la fecha el cargo de Inspector provincial por nombramiento directo de Gobernadores o de la propia Dirección General de Sanidad fue la dispensa de poseer el título de doctor para acudir a estas primeras oposiciones.

En el verano de 1904 se convocaron las primeras oposiciones para cubrir 48 plazas de Inspectores provinciales ${ }^{42}$ a las que acudieron 86 opositores $^{43}$ de los cuales aprobaron 58, diez más que las plazas a ocupar ${ }^{44,45,46}$. Estas oposiciones, se realizaron sin que se proveyeran en los presupuestos las cantidades destinaas a los sueldos de estos funcionarios, lo que provocó dificultades para la toma de posesión de aquellas personas que no contaban con medio de vida en la ciudad elegida en su turno correspondiente por lo que se concedieron licencias particulares para retrasar la toma de posesión del cargo ${ }^{47}$. Al mismo tiempo y debido a la falta de remuneración no se exigió incompatibilidades con otro tipo de trabajo. 
En diciembre de 1905 se dio luz verde al Ministerio de la Gobernación para presentar a las Cortes el proyecto de Ley que debía establecer la forma de remunerar a los Inspectores provinciales a través de los honorarios que estos debían de recaudar por sus servicios ${ }^{48}$, tal y como estaba previsto en los artículos 196 y 197 de la Instrucción General de Sanidad. Esta forma de remuneración era la establecida para pagar a los médicos de Sanidad marítima desde la Ley de Sanidad de 1855.

De forma paralela, y como medida de presión para la aprobación final de esta Ley se constituyó en diciembre de 1905 la Asociación Nacional de Inspectores de Sanidad, presidida por los dos Inspectores generales ${ }^{49}$. Esta Asociación, compuesta por los Inspectores provinciales que habían aprobado las primeras oposiciones, no sólo reclamaba la elaboración de las tarifas sanitarias sino que pretendía que se libraran las cantidades necesarias para su remuneración en los presupuestos para 1907 en forma de gratificación, lo que les permitiría seguir manteniendo otros empleos de forma simultanca ${ }^{49}$. También elaboraron un proyecto de Reglamento orgánico para que «cristalizara administrativamente el Cuerpo de Inspectores». Dicho proyecto de reglamento era muy ambicioso en sus planteamientos.

Entre sus reivindicaciones figuraba la independencia de Gobernadores civiles y alcaldes que les privaban de «potestad ejecutiva» y que su labor inspectora y de vigilancia alcanzara a todas las instituciones sanitarias aunque dependieran de otros ministerios. De esta forma pedían hacerse cargo de la Inspección escolar y estar presentes en las Juntas de Instrucción pública y Consejos universitarios ${ }^{49}$. Si esto se llevara a cabo, tal como afirmaba el secretario de la Asociación, José García Fraguas, «la higiene escolar no será una partida más en los gastos presupuestados por la Nación, sino un servicio de Beneficencia y Sanidad pública que mejore la raza, el país, la región y la familia por la virtud admirable de la educación individual» ${ }^{49}$. El alcance de sus peticiones también abarcaba a la inspección y vigilancia de las profesiones sanitarias al mismo tiempo que denunciaban a los Colegios Médicos «... que ni hacen ni dejan hacer parapetados tras un cacicato» pues «los funcionarios de la Administración sanitaria - junto con las Delegaciones de Hacienda, las Juntas de Gobierno y Patronato de los Titulares- son los verdaderos órganos para el cobro de las patentes, policía moral de los asociados y protección eficaz contra el intrusismo ${ }^{49}$.

Significativamente, el modelo de funcionariado que perseguía la Asociación no era el mantenido hasta la fecha por el Cuerpo de Sanidad exterior, cuyos miembros sólo podían aspirar como máximo a la categoría administrativa de Jefe de Negociado de primera clase $^{27}$. Según el reglamento propuesto, los Inspectores generales debían ser equiparados en «derecho y categoría» al nivel otorgado en la carrera administrativa a los Jefes de Administración de $1^{*}$ clase, los Inspectores provinciales que ocupasen los ocho números superiores del escalafón debían ser equiparados a los Jefes de Administración civil de $2^{a}$ clase, los que ocupasen del 8 al 16 a los Jefes de Administración de $3^{\mathrm{a}}$ clase $\mathrm{y}$, por último, los del 16 al 49 a los Jefes de Administración de $4^{a}$ clase $^{49}$.

Después de 26 meses de campaña lograron que el gobierno dictara, el 3 de enero de 1907 , la «Ley de los honorarios exigibles por los servicios de Sanidad interior ${ }^{50}$. En dicha Ley se detallaba el procedimiento mediante el cual los Inspectores provinciales debían recoger el dinero procedente de sus servicios y los usos a los que debía dedicarse. No obstante, y a pesar de que la Ley concedía un mes de plazo para que las tarifas se elaboraran, estas no se publicaron en la Gaceta hasta un año después $^{51,52}$.

Con la instauración de las tarifas sanitarias se abría una vía para la remuneración de los Inspectores provinciales pero no se solucionó el problema de forma definitiva. A los pocos meses de su aprobación, las medidas de inspección tomadas como consecuencia de la epidemia de cólera que amenazaba desde Rusia puso al descubierto que la actuación de los Inspectores por mandato directo de los Gobernadores civiles debía realizarse «de oficio» y por tanto «gratuitamente». Así lo estipulaba una Real Orden ${ }^{53}$ ante el apremio de algunos Inspectores de cobrar estos servicios a través 
de las tarifas sanitarias ${ }^{54}$; al mismo tiempo se les recordaba que debían «justificar una vez más su amor al servicio, ya que son deberes que les corresponden por razón del cargo».

La inadecuada remuneración de estos funcionarios fue el principal argumento para limitar el alcance de su dedicación al cargo y, tras una Real Orden de 3/10/1908 que obligaba a los Inspectores a tomar posesión de sus cargos sin más demora, se les concedió plena compatibilidad de su trabajo con cualquier otro sin más requisito que residir en la capital de su provincia ${ }^{55}$. También gozaron de privilegios a la hora de solicitar permutas, las cuales les eran concedidas sin necesidad de cumplir un año en su destino que era lo estipulado. Finalmente, se contempló una partida especial para pagar a los Inspectores provinciales dentro del crédito extraordinario de dos millones al que hicimos antes referencia. Esta remuneración se hizo en «concepto de gratificación anual por mensualidades vencidas» ${ }^{29}$ tal y como reivindicó la Asociación en 1905.

Otro de los problemas que en repetidas ocasiones fue planteado por los Inspectores provinciales fue la falta de apoyo administrativo en los despachos que ocupaban dentro de los Gobiernos civiles. En 1912, tras una petición de estos capitaneada por el Inspector provincial de Madrid, José Call y Morros (1858c.1923) se les concedió que, con cargo a la partida de cada Gobierno civil se atendiera mensualmente al suministro de impresos y gastos de escritorio siempre y cuando fueran «de absoluta necesidad» ${ }^{56}$.

A pesar de estos avances en la definitiva organización del Cuerpo, todavía quedaban varias Inspecciones provinciales sin proveer, fruto de las renuncias y constantes traslados de sus titulares desde que se celebraron las oposiciones de 1904. Por este motivo se convocaron en 1909 unas segundas oposiciones y se elevó el número de Inspectores provinciales a $60^{57}$. Esta medida no palió el problema de las plazas que quedaban vacantes. Todavía en 1915 una Real Orden reconocía que esta medida no había surtido efecto pues tras el tiempo transcurrido, «no se ha manifestado en gencral interés ni buena disposición por parte del personal para ocupar vacantes», siendo desem- peñadas interinamente por los subdelegados. La solución que se ofreció fue conceder a los Inspectores provinciales que se encontraban en excedencia los mismos derechos para cubrir esas vacantes que los que poseían los funcionarios en activo ${ }^{58}$.

La reorganización sanitaria que se llevó a cabo en fechas de las segundas oposiciones, al igual que ocurriera con los médicos de Sanidad exterior, también afectó a los requisitos que debía reunir el aspirante a Inspector provincial: se exigió una edad máxima de 50 años y el temario incluyó por primera vez un amplio número de lecciones dedicadas a Bacteriología ${ }^{59}$. Esta evolución en las exigencias de conocimientos a los Inspectores Provinciales de Sanidad se hizo aun más patente en 1914 donde el temario de las oposiciones realizadas en este año fue prácticamente sobre Bacteriología y Microbiología ${ }^{60,61}$.

Precisamente, las nuevas orientaciones de la Sanidad nacional, basadas en las corrientes bacteriológicas y que tuvieron, entre otras consecuencias la suspensión del sistema cuarentenario en la Sanidad exterior, unido a la importancia que aun se le daban a las enfermedades epidémicas en nuestro país, hizo que el Estado reforzara el sistema de inspección creando un nuevo cargo dentro de los Cuerpos de Sanidad del Estado. La nueva figura, creada en la Ley de presupuestos de 1908, fue la de Inspector de Servicios sanitarios. Este puesto estaba a las órdenes inmediatas de los Inspectores Generales y su misión consistía en acudir inmediatamente allí donde las necesidades lo exigieran «para que las funciones, siempre urgentes, de la sanidad no sufran retraso ni interrupción alguna». En diciembre de 1908 se convocaron cuatro plazas: una para los servicios de Sanidad interior, otra para los de exterior, otros para Servicios farmacéuticos y otra para los de Sanidad veterinaria. Las dos primeras debían ser desempeñadas por médicos, la tercera por un farmacéutico y la cuarta por un veterinario ${ }^{62}$. La plaza de Inspector médico de servicio de la Sanidad interior no se cubrió y la Ley de presupuestos de 1913 varió las condiciones establecidas para su provisión $\mathrm{y}$ exigió que el cargo debía ser ocupado por un miembro del Cuerpo de Inspectores provincia- 
les de Sanidad. La remuneración de 6.000 pesetas anuales coincidía con la percibida por los Inspectores de máxima categoría y también en concepto de gratificación lo que le permitía la compatibilidad con cualquier otro sueldo percibido con fondos públicos ${ }^{63}$. Esta última condición era fundamental, pues para la provisión de esta plaza tendrían preferencia los catedráticos de la Facultad de Medicina. Además debían poseer «competencia profesional notoria, aptitud física conveniente y residencia fija en la Corte» y poseer conocimientos de bacteriología, química y administración sanitaria $^{64}$.

Las reivindicaciones hechas por la Asociación de Inspectores de Sanidad acerca de la ampliación de sus funciones a dirigir todas aquellas dependientes de otros ministerios no sólo no se vieron cumplidas sino que los distintos ministerios siguieron desarrollando la labor sanitaria en su ámbito de acción. Este fue el caso del Ministerio de Fomento que bajo el gobierno liberal creó por R.D. de 25/9/1910, el Cuerpo de Inspectores de Sanidad del Campo. No obstante, en 1912, vio la luz el tan esperado Reglamento del Cuerpo de Inspectores provinciales cuyo borrador había sido redactado por una Comisión elegida por los propios Inspectores ${ }^{65}$.

Este Reglamento, con tan sólo 14 artículos, consideraba a las Inspecciones Provinciales como «organismos especiales de la Administración pública» para el «conocimiento, tramitación, informe, y en algunos casos resolución de los asuntos referentes a Sanidad, Higiene y personal sanitario de las provincias». Asimismo confirmaba la constitución de un «Cuerpo facultativo con todas las atribuciones y derechos en situación activa o pasiva que les estén asignados por las leyes y disposiciones vigentes». El ingreso en el mismo sólo se realizaría por oposición y sus miembros conformarían un escalafón especial ${ }^{66}$. Además de confirmarse las prebendas que ya disfrutaban en materia de inamovilidad, excedencias, permutas y licencias, el Reglamento especificaba que las plazas vacantes en las distintas provincias se proveyeran por concursos cerrados entre los Inspectores provinciales, los cuales podrían elegir por el orden numérico del esca- lafón. Como novedades introducidas en este Reglamento tenemos que señalar la concesión a los Inspectores provinciales del derecho a usar en los actos oficiales el «uniforme que se acuerde» y a recibir indemnizaciones por gastos de viaje. Las dietas, sin embargo, debían ser pagadas por el organismo o persona particular que requiriese sus servicios, ya que, según reconocía el preámbulo de la Real Orden, «en nuestra legislación sanitaria, hoy no están en aplicación». Por último, dos artículos iban dirigidos a mejorar el servicio de las Inspecciones provinciales. En primer lugar se estipulaba que el subdelegado de medicina más antiguo en la capital sustituyera al Inspector provincial en cualquier circunstancia. En segundo lugar, se declaraba el cargo de Inspector incompatible «con todo otro destino retribuido que pueda impedir el ejercicio constante de sus funciones», es decir aquellos destinos fuera de la capital de la provincia tal y como habían pedido en diferentes ocasiones los propios Inspectores provinciales.

En 1916 el Cuerpo de Inspectores provinciales estaba perfectamente asentado tanto desde el punto de vista administrativo como profesional. En este año en el que quedaron cubiertas todas las plazas existentes con Inspectores titulares, estos comenzaron a colaborar con la revista recién creada La Medicina Social Española, publicación que compartían como órgano de expresión con la Sociedad Española de Higiene tal y como rezaba en su portada. Al mismo tiempo se dio el primer paso para la futura reunificación de los Cuerpos de Sanidad al transformarse las dos Inspecciones Generales en una sola Inspección General de Sanidad del Reino y una Subinspección General ${ }^{67}$. Para el primer cargo se nombró titular al que ya lo era de Sanidad exterior desde $1909^{68}$, Manuel Martín Salazar (1854-1936) y para el segundo al que era Inspector General de Sanidad interior, Eloy Bejarano. Este último fue sustituido, un año después, por Jorge Francisco Tello y Muñoz (n. 1880) ${ }^{69}$.

Auspiciada por el flamante Inspector General, en noviembre de ese año los Inspectores provinciales celebraron su primera asamblea «para conocernos todos los procedentes de 
oposiciones distintas y para darnos mutua cuenta de la labor sanitaria y del modo de realizarla por cada uno en su respectiva provincia ${ }^{70}$. En las conclusiones aprobadas ${ }^{71}$ los participantes ofrecieron a las autoridades, además de unas bases para la elaboración de una «Ley de Sanidad» y de una «Ley de profilaxis pública contra las enfermedades infecciosas», sus propuestas sobre organización sanitaria fundidas con sus reivindicaciones profesionales.

En primer lugar propusieron que la denominación de Inspector fuese sustituida por la de Jefe, cambio que reflejaría la anhelada posesión de poder ejecutivo en materia sanitaria - tal y como proponían en otra de las conclusiones - y marcaría la distancia con el poder político. Esta modificación no afectaría a los Inspectores municipales de Sanidad que pasarían a llamarse Inspectores municipales de salubridad pública. La jerarquía de mando administrativo no sólo se reforzaba — se pedía que los Inspectores municipales no tuvieran carácter de autoridad - sino que también se ampliaba al contemplar la existencia de dos Subjefes superiores de Sanidad, uno para Sanidad interior y otro para la Sanidad exterior. Para el desempeño del cargo de Subjefe de Sanidad interior, se contemplaba que fuese ocupado por un Inspector provincial mediante un concurso de antiguiedad, lo que aumentaría sus posibilidades de promoción profesional. Para el desarrollo efectivo de sus funciones sanitarias los Inspectores reclamaban la creación en todas las provincias de un Instituto de Higiene, un Parque de desinfección y una brigada sanitaria, instituciones que dependerían del Jefe provincial «en igual forma que el [Instituto] nacional de la Jefatura Superior».

La consideración administrativa a la que aspiraban los Inspectores provinciales era la que disfrutaban los Delegados de Hacienda con los que pedían ser asimilados en todos los conceptos relacionados con su retribución, jubilación y derechos pasivos. No era casual, pues el Ministerio de Hacienda y gracias a los mandatos de Fernández Villaverde (tanto como ministro o presidente del Consejo) era el Cuerpo del Estado que gozaba de mayores ventajas profesionales ${ }^{16}$. En este sentido, exigían que, mientras la remuneración no fuese suficiente para asegurar la independencia absoluta del ejercicio del cargo, se les compatibilizara su dedicación con otros empleos públicos que no les obligara a abandonar la capital de la provincia.

Para el ingreso en el Cuerpo de Jefes provinciales se pedía que sólo se realizara por oposición pública entre doctores con más de ocho años de experiencia en la profesión médica además de exigírseles estar en posesión del título de «Oficial sanitario». Dicho título, que suponía una novedad en las propuestas realizadas por los Inspectores, lo otorgaría el Instituto Nacional de Higiene Alfonso XIII mediante examen. Para la preparación de los futuros aspirantes se proponía la creación de cursos de nueve meses de duración en total, siete en el Instituto de Alfonso XIII y dos en las oficinas de Sanidad en el Ministerio de la Gobernación.

Es interesante señalar la ausencia entre sus reivindicaciones de la creación de un Ministerio de Sanidad a pesar de que, en su órgano de expresión, varios de los Inspectores se pronunciaron en este sentido ${ }^{72,73}$. Posiblemente, las palabras inaugurales del Ministro de la Gobernación, Ruiz Jiménez, pidiendo «un alto sentido de la realidad» para que no se malograsen sus iniciativas hizo desistir a los asambleístas de tal propósito. Por el contrario, para los Inspectores era ineludible que el Gobierno asumiera al completo las conclusiones de la Asamblea para «el progreso sanitario de España» pues «... cuanto se ha propuesto en esta Asamblea, tiene un punto de vista científico que garantiza su eficacia cierta; se conforma con la justicia, en tanto que todo ello es necesario para proteger la salud y la vida de los ciudadanos; responde a las exigencias del patriotismo porque tan vasto programa tiene por objeto y fin conservar y acrecer el capital humano, del cual no puede dejarse perder indebidamente la más mínima parte sin atentar contra la seguridad y grandeza de la patrias ${ }^{70}$.

\section{Las Instituciones sanitarias}

El tercer elemento de la Sanidad Nacional lo configuraban los empleados técnicos que trabajaban en las instituciones sanitarias del 
Estado que en un primer momento se limitaba al Instituto general de Vacunación creado en 1874 y que posteriormente quedó incorporado al Instituto de Sueroterapia, Vacunación y Bacteriología de Alfonso XIII creado en 1899.

El Instituto general de Vacunación, que entró en funcionamiento en marzo de 1874 como «Centro provisional» ${ }^{74}$, fue puesto bajo la inspección de la Real Academia de Medicina en 1875 (R.O. 17/4/1875) cuyos informes emitidos un año después persuadieron a la Administración de la conveniencia de su mantenimiento y desarrollo ${ }^{75}$. El nombramiento del personal facultativo era competencia del Gobierno que fijó la plantilla, en 1876, en cinco médicos vacunadores, cuatro practicantes y tres mozos ${ }^{75}$. En 1877 (R.O. 1/7/1877), el centro pasó a denominarse Instituto de Vacunación del Estado y quedó dividido en dos secciones, una Central y otra de Visitadores. En 1885, el Instituto de Vacunación, cuyo número de médicos ascendía en esa fecha a 16 , fue reorganizado para equiparar a sus miembros con el Cuerpo facultativo de Beneficencia General ambos dependientes de la Dirección General de Beneficencia y Sanidad ${ }^{76}$. De esta forma se creó el Cuerpo médico de Vacunadores del Estado —adelantándose en un año a la creación del Cuerpo de Sanidad Marítimaque por su novedad tuvo que regirse por el Reglamento orgánico del Cuerpo facultativo de Beneficencia General (R.D. 23/12/1884). Según este Reglamento, el ingreso en el Cuerpo debía realizarse sólo por oposición y los ascensos debían seguir una rigurosa escala por antiguiedad. No obstante, el respeto a los «derechos adquiridos» permitía la continuidad de los facultativos con seis años de servicio en el Instituto o diez en el ramo de la beneficencia y sanidad. Esta reorganización rebajó la plantilla a tan sólo diez facultativos cuyos interinos, un año después, seguían en sus puestos sin que se hubiesen realizado las previstas oposiciones ${ }^{77}$.

En 1894 un Real Decreto creó el Instituto Nacional de Bacteriología e Higiene ${ }^{78,79}$ que, a pesar de contar con los fondos necesarios para la construcción de un edificio y nombrarse a Amalio Gimeno como director, nunca llegó a funcionar. Entre las funciones que debía desarrollar dicho instituto se encontraban los «estu- dios y trabajos bacteriológicos y químicos con aplicación a los servicios sanitarios» elementos que, según se afirmaba en el preámbulo del Decreto que creaba el instituto, habían abierto una nueva vía en la lucha contra las epidemias «en que los hallazgos son tan frecuentes como pródigos en éxitos». Los mismos objetivos perseguía, cinco años después, el Instituto de Sueroterapia, Vacunación y Bacteriología de Alfonso XIII, creado en 1899 por iniciativa del Director General de Sanidad Carlos María Cortezo $^{80,81}$, a la par que se disolvían el Instituto de Vacunación del Estado y el fallido Instituto Central de Bacteriología e Higiene ${ }^{82}$. Esta nueva institución surgía además como «Escuela de bacteriología» donde se impartirían enseñanzas prácticas de dicha materia «en su relación con la higiene pública y la epidemiología». El Instituto se dividía en tres secciones: una «de análisis bacteriológicos y enseñanza de su técnica», otra «de Sueroterapia y obtención de sueros y vacunas» y, por último, otra «de Inoculaciones y de la vacuna». Al frente de la institución estaría una Comisión técnica y otra administrativa de entre los que se elegirían sus respectivos presidentes. Para cubrir las necesidades de personal, el nuevo instituto contaba con los empleados del antiguo Instituto de Vacunación al que se le respetaban los derechos adquiridos. Significativamente, y a pesar de haberse legislado en sentido contrario al crearse el Cuerpo médico de vacunadores del Estado, el «personal médico, inoculadores y vacunadores» serían nombrados por el Gobierno mientras que, por el contrario, se disponía que el personal de profesores de la Escuela de bacteriología y de ayudantes de laboratorio se proveyera por oposición. El Real Decreto prohibía las permutas y traslaciones entre el personal facultativo de las dos primeras secciones con la tercera. En 1904, la Instrucción general de Sanidad se limitó a confirmar la existencia del Instituto y lo mantuvo anejo al Ministerio de la Gobernación bajo la recién creada Inspección General de Sanidad interior.

En 1908 se dispuso la transformación del Instituto de Sueroterapia, Vacunación y Bacteriología de Alfonso XIII en el Instituto Nacional de Higiene de Alfonso XIII. Al mismo tiempo se iniciaba la construcción de un edifi- 
cio de nueva planta más acorde con el papel preeminente que debía ocupar el laboratorio una vez reconocida la importancia de las técnicas bacteriológicas en el desarrollo de la higiene pública ${ }^{83}$. Tal como se afirmaba desde la propia administración sanitaria en 1909 «la higiene nace en los laboratorios, y donde no hay laboratorios abundantes, el progreso se cumple tarde, mal y de prestado ${ }^{29}$. En consecuencia, el nuevo Instituto heredaba la función docente conferida a la institución desaparecida, y presumiblemente inédita, de formar un amplio equipo de sanitarios preparados para desarrollar las nuevas prácticas antibacterianas. Tal como esperaba la propia Administración el Instituto sería «la escuela, la pepinière de los futuros higienistas españoles, y de él habrá de salir, pertrechado de todas armas, el personal destinado a realizar la obra sagrada de reconstitución étnica nacional» ${ }^{29}$. En 1914 se justificó la necesidad de que el Instituto de Alfonso XIII especializara a los aspirantes a cargos oficiales de Sanidad ya que su debida formación no podía llevarse a cabo en las facultades de medicina, al no existir ninguna cátedra especial donde se enseñara microbiología, materia considerada «la base de la Sanidad ${ }^{28}$. El Instituto estrenó su labor docente impartiendo prácticas de bacteriología a los miembros del Cuerpo de Sanidad exterior, como ya hemos visto, pero el primer curso de ampliación de estudios sanitarios, tal y como habían reivindicado los Inspectores provinciales en 1916, comenzó el 23 de octubre de 1917 y se prolongó hasta mayo de 1918 con un total de nueve profesores. Los doce alumnos admitidos debían superar un examen al finalizar los estudios para recibir el certificado de aptitud ${ }^{84}$.

El personal técnico de este Instituto se convirtió en estable a partir de 1911 al legislarse la inamovilidad del mismo salvo por causa justificada en el «oportuno expediente ${ }^{85}$. A pesar de que en este mismo Decreto se contempló que el ingreso en el Instituto de todo su personal se realizara en adelante por concurso, lo cierto es que hasta 1916, fecha en el que el nuevo Reglamento vio la luz, no quedó regulada esta posibilidad ${ }^{86}$. En 1918, la plantilla del Instituto de Alfonso XIII contaba con 25 médicos, un químico, un veterinario y dos practicantes 8 .
Otras instituciones sanitarias, creadas por el Estado a raíz del presupuesto extraordinario de 1908, fueron dos Sanatorios Marítimos situados en Oza (La Coruña) y Pedrosa (Santander) que comenzaron a funcionar en el verano de 1910. Dichos centros, dedicados a la recuperación de niños «pretuberculosos» y a la curación de niños con tuberculosis osteoarticulares, se establecieron en los edificios de los antiguos lazaretos que existían en estas poblaciones y que se encontraban sin función desde los acuerdos de París de $1903^{28}$. El Estado se hacía cargo del mantenimiento de los sanatorios y del sueldo de sus empleados pero la estancia de los niños debía ser cubierta por parte de las entidades que los enviaban tales como diputaciones, ayuntamientos o ligas benéficas ${ }^{83}$. Las plantillas aprobadas en septiembre de 1918 recogían la existencia de un director médico y un médico auxiliar como todo el personal facultativo del Sanatorio de Pedrosa mientras que en Oza, además del director, figuraban un Jefe del servicio quirúrgico y tres médicos auxiliares ${ }^{89}$.

\section{UNO PERO NO INDIVISIBLE. EL PROCESO DE UNIFICACIÓN DE LOS CUERPOS DE SANIDAD (1919-1926)}

La reforma general de la Administración propiciada por la Ley General de funcionarios y empleados públicos de 22/7/1918 estipulaba que se debía reducir el personal «al estrictamente necesario» lo que importaría, como mínimo, una tercera parte de la suma consignada en los créditos presupuestarios vigentes para gasto de personal. Sin embargo, para los Cuerpos especiales se estipuló que el Consejo de Ministros acordaría lo que considerase oportuno ${ }^{16}$. Este fue el caso de los funcionarios de Sanidad que no sólo se libraron del recorte sino que, además, se beneficiaron del aumento de sueldo reglamentario. Presumiblemente, la alarma social provocada por la epidemia de gripe que coincidió con la reforma, supuso un argumento mas que suficiente para mantener a todos los sanitarios en sus puestos. Seis meses después de promulgarse esta Ley de funcionarios y empleados públicos, el Gobierno liberal reestructuró la organización sanitaria bajo la iniciativa del Ministro de la Gobernación, el médico Amalio Gimeno ${ }^{90}$. 
Entre las reformas más significativas, que derogaban sustancialmente la Instrucción General de Sanidad, destaca la división, en tres secciones diferentes, de los servicios de la Administración Central de Sanidad, subordinadas a la Inspección general: una de Sanidad interior, otra de Sanidad exterior y otra de Institutos de Higiene y demás instituciones sanitarias. Cada sección tendría un Subinspector general que sería el Jefe de cada sección y del Cuerpo facultativo correspondiente. De esta forma se perfilaban las tres ramas de la Sanidad nacional con la creación de un nuevo Cuerpo sanitario constituido por el personal del Instituto Nacional de Higiene Alfonso XIII y por el de los institutos regionales que se fueran creando. El artículo $5^{\circ}$ de este Real Decreto especificaba que el ingreso en este Cuerpo sería por concurso-oposición -y no sólo por concurso como anteriormente-y los aspirantes deberían presentar una certificación de preparación sanitaria expedida por el propio Instituto Nacional de Higiene. Tras el nombramiento de los Subinspectores (Leonardo Rodrigo Lavín, Sanidad interior; Manuel Romero, Sanidad exterior y Francisco Murillo, Instituciones sanitarias) el escalafón de su personal se publicó muy rápidamente sólo dos meses después ${ }^{91}$.

El Cuerpo de Sanidad exterior no fue modificado pues, según este Decreto, «ha llegado a un estado que no exige por ahora más que aquellas reformas que con el tiempo se crean convenientes para adaptarlo a la evolución de la higiene internacional». Sin embargo, el Cuerpo de Sanidad interior sí fue objeto de una nueva reestructuración al entenderse que todavía no tenía «la amplitud necesaria para realizar sus fines». Esta ampliación se refería fundamentalmente a la incorporación «como colaboradores y auxiliares de los Inspectores provinciales» a los miembros del Cuerpo de Sanidad del Campo ${ }^{92}$ en situación de excedencia desde que se suprimiera este Cuerpo por Real Decreto de 23/10/1918 dentro de la reforma general de la Administración. En efecto, a pesar de que el Reglamento de este Cuerpo databa de poco tiempo atrás ${ }^{93}$ la Administración lo eliminó por entender que «su escasa eficacia es notoria... por defectos de su organización y por la escasez de medios». La refun- dición se realizó en febrero de $1919^{94}$ al mismo tiempo que el servicio se declaraba «a extinguir» conforme sus plazas fueran quedando vacantes. La plantilla la componían: un Inspector-Jefe, un Inspector Secretario, quince Inspectores regionales, dos auxiliares técnicos y un auxiliar. Al mes siguiente de la refundición, la Subcomisión de Presupuestos del Congreso negó al Ministro Gimeno un crédito para la organización de este nuevo servicio ${ }^{16}$ lo que explicaría que en 1926 este personal continuara excedente "cobrando las dos terceras partes de sus sueldos, sin misión alguna ni función que cumplir» ${ }^{95}$.

Junto a esta incorporación, los Inspectores provinciales podrían contar en adelante con los subdelegados de Sanidad, convertidos por tercera vez, en Inspectores de Sanidad de distrito o partido judicial. Para que esta función fuera efectiva se imponía que en lo sucesivo, los aspirantes dejaran de ser nombrados por los Gobernadores civiles e ingresaran por oposición en la que debían demostrar sus conocimientos en materia sanitaria. A partir de entonces, serían remunerados a cargo de los presupuestos generales del Estado. Los actuales subdelegados debían someterse a una prueba de aptitud, sobre materias de epidemiología y legislación sanitaria, que les daría derecho, caso de superarla, a mantenerse en sus cargos. No debemos olvidar que, hasta la fecha, los subdelegados, como reconocía el preámbulo del Decreto que estamos comentando, estuvieron «ocupados hasta ahora más bien en atenciones oficiales de otra índole». Entre estas funciones oficiales, por las cuales cobraban sus emolumentos sobre la base de las tarifas sanitarias, se encontraban las de registrar los títulos de los médicos que ejercían en su distrito, anotar en un libro-registro los casos de intrusismo y los castigos impuestos, garantizar la autenticidad de las firmas en los certificados de enajenados y dementes y la fiscalización de los embalsamamientos y exhumaciones.

Por último, la reforma más importante que introducía este Decreto respondía a una parte de las aspiraciones de poder ejecutivo reclamadas por los Inspectores provinciales tres años antes. En efecto, entre las facultades que tendrán estos funcionarios a partir de ese mo- 
mento se incluyó la facultad de hacer efectivas las sanciones impuestas por delitos sanitarios. Esta autoridad, reconocida por primera vez al Inspector provincial, le vendría conferida directamente del Ministro de la Gobernación a través del Inspector y Subinspector General de Sanidad. Hasta la fecha la única autoridad gubernativa provincial «con la potestad de mando suficiente» para imponer sanciones era el Gobernador civil. Esta reforma fue valorada muy positivamente pucs una de las mayores trabas con las que tropezaban los funcionarios sanitarios era «la esterilidad de sus determinaciones en materia de penalidad ${ }^{95}$. Pensamos que estas concesiones no son ajenas a la situación sociopolítica del país. Si consultamos una cronología general leeremos: agudización del pistolerismo, huelgas y agitaciones, actividades de organizaciones obreras de $\operatorname{clasc}^{96}$; por tanto, se hacía necesario reforzar y ampliar el ámbito de actuación de agentes del orden, y sabemos que el orden sanitario ha sido una buena fuente de modelos transferibles al orden social.

En septiembre de 1919, el Gobierno conservador entrante tras la crisis de julio, volvió a modificar las plantillas del personal sanitario cumpliendo la Ley de 14/8/1919 (Gaceta 15/8/1919). Esta Ley perseguía «dar proporcionalidad a los diferentes Cuerpos civiles» en categoría y sueldos debido en parte a los privilegios de los que habían gozado los Cuerpos de Correos y Telégrafos y los del Ministerio de Hacienda cuyos funcionarios habían conseguido aisladamente una reforma de plantillas con posterioridad a la Ley General de funcionarios y empleados públicos de 1918 con el consiguiente agravio comparativo ${ }^{16}$. El aumento autorizado podía alcanzar hasta el 14 por ciento de los presupuestos vigentes y fue aplicado mediante Real Decreto de 2/9/1919 ${ }^{97}$. El Cuerpo de Sanidad exterior fue el único afectado en cuanto al número de su personal y categorías administrativas. En primer lugar, se suprimió la barrera legal que les impedía ascender por encima de Jefe de Negociado de primera clase -en las nuevas plantillas ya aparecía un Jefe de Administración de segunda y tres Jefes de Administración de tercera- pero de los 75 médicos que formaban el Cuerpo tras la reforma de 1918 sólo quedaron 25. Esto, junto con las reformas que se hicieron en Sanidad interior, muestra el cambio que había experimentado el programa sanitario con relación a dónde radicaba el peligro para la salud de la nación.

La siguiente iniciativa del Gobierno conservador, al mes siguiente de la modificación de plantillas, fue una amplia «revisión y ampliación» del Reglamento del Cuerpo de Inspectores de Sanidad provincial, completamente obsoleto tras las distintas reformas que afectaron a la organización del Cuerpo desde que se aprobara aquel en $1912^{98}$. Aparte de una detallada descripción de las funciones que debía de realizar el Inspector provincial, este Reglamento aportó pocas novedades en la organización del Cuerpo e ignoraba las reivindicaciones efectuadas por la Asamblea de inspectores realizada en 1916. Hasta la fecha, las conquistas de los Inspectores se habían reducido a que se incluyera en los presupuestos de las Diputaciones provinciales una partida de 750 pesetas como consignación para los gastos de material ordinario y de oficina de las Secretarías de las Juntas provinciales de Sanidad ${ }^{99}$. El Reglamento establecía en 65 el número máximo de inspectores que podían pertenecer al Cuerpo, incluyendo en esta cifra, junto a los Inspectores en activo, a los excedentes, aspirantes y en expectación de destino. Además, se suprimió el requisito de poseer el título de doctor y contar con un mínimo de años de ejercicio profesional para ingresar en el Cuerpo pero, a cambio, se especificó que la edad de los aspirantes, en el momento de realizarse las pruebas de ingreso, debía estar comprendida entre 25 y 45 años, edad, esta última, que se redujo a 40 en $1923^{100}$. Por otra parte, el nuevo Reglamento disponía que el cargo de Subinspector General - Jefe del Cuerpo y de la Sección de Sanidad interior- se proveyera por concurso de méritos y de antigüedad entre los Inspectores provinciales. Por último, el Reglamento salvaguardaba los derechos adquiridos de los miembros del Cuerpo en materia de compatibilidad al señalar que, en caso de establecerse, sólo se aplicarían a «los Inspectores que ingresen con posterioridad a la aprobación de este reglamento».

El escalafón provisional del Cuerpo de Inspectores provinciales tras las distintas re- 
formas apareció en enero de 1921 con el Subdirector General de Sanidad interior, Román García Durán (n. 1863) —nombrado en octubre del año anterior - a la cabeza. Este escalafón detallaba por primera vez, además de los destinos y sueldos, la fecha de nacimiento, la del primer nombramiento y el tiempo de servicio en el Cuerpo. El número de miembros del escalafón ascendía a 56 y estaba formado, además del Subinspector, por un auxiliar en la Inspección general, el Inspector de servicios, 45 inspectores de Sanidad, 5 excedentes y 3 en expectativa de destino ${ }^{101}$

La creación, en 1922, de la Dirección General de Sanidad del Reino, no afectó a la estructura de la organización sanitaria configurada por la reforma de Amalio Gimeno ${ }^{102}$, El cambio de nombre de la Inspección General afectaría también a las Subinspecciones que pasarían a denominarse Inspección General de Sanidad interior, de Sanidad exterior y de Instituciones Sanitarias. La reaparición de esta Dirección General atendía a la necesidad, según el preámbulo del Real Decreto, de aumentar la utilidad de los servicios sanitarios «dentro de la mayor economía» e impulsados por una «unidad directiva» que acomodara el organismo sanitario actual a «las demandas de la vida moderna». Entre estas demandas, el legislador enumeraba la puesta en marcha del Seguro Obligatorio de Enfermedad y la oportuna dirección de la iniciativa privada en su lucha contra las enfermedades infecciosas. En otros países, la respuesta había sido la creación de Ministerios de Sanidad «dotados de los elementos y créditos indispensables para realizar la magna obra profiláctica y regeneradora que aguardan los pueblos destrozados por la miseria o acuciados por el malestar económico e industrial». Ante la imposibilidad de poder contar en España con un Ministerio del ramo, la creación de la Dirección General de Sanidad secundaría estas iniciativas al dar mayor realce a la Sanidad y «mayor facilidad para el cumplimiento de su misión». El carácter «técnico» de la nueva Dirección Genera' se reforzaba al contemplar el Artículo $5^{\circ}$ que, en caso de vacante, se proveyera mediante concurso entre doctores en Medicina especializados en materias sanitarias y de higiene pública.
Las expectativas creadas en buena parte de las clases medias por el Golpe de Estado del General Primo de Rivera ${ }^{103}$, reavivó la posibilidad de acometer una reforma radical de la Sanidad lo que animó al Director General de Sanidad a presentar al Directorio militar, en noviembre de 1923, un ambicioso proyecto de Ley de Reorganización Sanitaria, elaborado el mes anterior por una Comisión de notables presidida por Pulido y que tenía como vocales a Martín Salazar, Murillo, Durán, Mestre, García Izcara, Piñerúa, Casas, Recasens, Tello, Pittaluga, Blanc, Sanchiz Bergón, Marañón, Huertas, Gallego y Ramos ${ }^{104}$. Este proyecto incluía en sus bases más significativas la creación de un Ministerio de Trabajo y Sanidad, la creación de Institutos de Higiene y Brigadas sanitarias en todas las provincias y la dependencia de la Dirección General de toda la Beneficencia oficial de carácter sanitario ${ }^{105}$. La respuesta del General Severiano Martínez Anido, entonces Subsecretario de Gobernación y significativamente responsable del nombramiento de la Comisión de notables, fue negativa arguyendo que «... los tiempos no están para perderse en la gestión de proyectos... [que] desatienden y esquivan las realidades inmediatas, a las cuales hay que servir con el apremio que las circunstancias exigen... [ya] será momento oportuno de pensar en organizaciones más sutiles y complicadas» ${ }^{106}$. Lo que ofrecía el Directorio eran «realidades de acción» como ya había demostrado en el poco tiempo transcurrido desde el Golpe de Estado.

En efecto, la organización sanitaria no se libró de las medidas dictatoriales que pretendían dotar al Estado de una Administración que sustituyera a «los profesionales de la política» basada en el ejército como pieza de recambio y, en una segunda etapa desde 1926, en la incorporación de una clase política fiel a la persona del dictador ${ }^{107}$. La primera medida tomada, aparte de la suspensión de todas las oposiciones a cargos públicos convocadas antes del Golpe de Estado, fue un Decreto en contra de la inamovilidad y compatibilidades de los Inspectores provinciales de Sanidad ${ }^{108}$. El Real Decreto disponía el traslado forzoso de los Inspectores provinciales por «conveniencias y necesidades del servicio» y se disponía el límite de cinco años como el tiempo máxi- 
mo de permanencia en una provincia. Además se declaraban incompatibles los sueldos de los Inspectores provinciales «con el devengo de otros haberes del Estado, la Provincia o el Municipio... y no podrán ejercer, fuera de su profesión, la industria ni el comercio, ni coparticipar en Empresas de la provincia de su destino».

El riesgo de no encontrar personal cualificado dispuesto a ingresar en el Cuerpo bajo estas condiciones, inconveniente que se apuntó desde las revistas profesionales ${ }^{109}$, no importó al Directorio ya que dejaba las manos libres al gobierno para "colocar sus piezas» en las ciudades más conflictivas o influyentes. En efecto, si el Real Decreto no se aplicó en lo referente a las incompatibilidades, debido a que prácticamente todos los Inspectores incumplían este requisito ${ }^{110}$, si fue utilizado para mover de su provincia a un total de diez Inspectores ${ }^{111}$. Este era el caso del Comandante médico José Alberto Palanca y Martínez Fortún (1888-1973), recién ingresado en el Cuerpo y que compaginaba su cargo en Sevilla con el de catedrático de Higiene. Este médico fue reclamado por Martínez Anido para la Inspección de Madrid tras una Real Orden que autorizaba al Subsecretario del Ministerio de la Gobernación a «elegir Subinspector de Sanidad o Inspector provincial de Sanidad en Madrid, al Inspector que reuniese las mejores condiciones ${ }^{12}$, previamente esta plaza había quedado desierta tras el traslado forzoso de José Call y Morros a Lérida. Desde la capital del Estado, la influencia de Palanca se dejará sentir en las esferas gubernamentales y entre sus compañeros del Cuerpo.

Todas estas incidencias, sobre todo el rechazo al proyecto de Ley de reforma sanitaria, hicieron que el Director General de Sanidad, Martín Salazar, presentara su dimisión en diciembre de ese año. El cargo fue ocupado inmediatamente, y sin concurso de méritos como estaba legislado, por Francisco Murillo Palacios (1865-1944) hasta la fecha Inspector General de Instituciones sanitarias ${ }^{113}$. Este nuevo Director General, no obstante, llevará a cabo muchas de las iniciativas recogidas por Martín Salazar en su proyecto sanitario como fue la creación de la Escuela Nacional de Sa- nidad al año siguiente de su nombramiento. Las primeras medidas tomadas por el nuevo Director General de Sanidad con respecto a la organización sanitaria iban acordes con el ideario de la recién instaurada Dictadura. En primer lugar instauró los Tribunales de Honor para juzgar a los funcionarios médicos dependientes de la Dirección General de Sanidad «por actos $\mathrm{u}$ omisiones que, no habiendo sido objeto de resolución administrativa, impliquen deshonor o desprestigio de aquellos» ${ }^{14}$; y en segundo lugar, poner de parte del nuevo régimen al numeroso Cuerpo de Subdelegados al intentar llevar adelante, ahora por cuarta vez, su definitiva reorganización ${ }^{115,95}$.

Esta última pretensión tampoco pudo llevarse a cabo bajo la Dictadura que se encontraba también con el problema de organizar la Sanidad provincial y municipal lo que conllevaba una redistribución de competencias. En efecto, la figura de Subdelegado, a pesar de desempeñar servicios de la exclusiva competencia municipal, estaba independizada de las corporaciones locales las cuales, a su vez, contaban con sus propios Inspectores de Sanidad para similares tareas. Por otra parte, las funciones de los Inspectores provinciales quedarían mermadas si el cargo de Subdelegado asumiera efectivamente las inspecciones de distrito, sin olvidar las aspiraciones de aquellos de hacerse cargo del control de la profesión médica y el intrusismo tal y como hemos visto anteriormente. También tenemos que tener en cuenta que las funciones que ejercían los subdelegados eran retribuidas mediante el cobro de las tarifas sanitarias lo que suponía un sobresueldo para el profesional que las desempeñara. Este último punto era considerado por algunos de los subdelegados como el verdadero «caballo de batalla» ${ }^{116}$. El Reglamento de Sanidad municipal (R.D. 9/2/1925) favoreció a las corporaciones locales al incluir en su artículo 43 que todos los médicos titulares fuesen inspectores municipales de Sanidad en sus respectivos distritos, incluso en las cabezas de partido judicial y en las capitales de provincia que contaran con menos de 30.000 habitantes. Además, el artículo 46 dejaba bien claro que los subdelegados no disfrutaban de sueldo ni gratificación aparte del cobro de las tarifas sanitarias. Antes de la aprobación del 
Reglamento de Sanidad municipal se había publicado en la Gaceta el programa y el reglamento para las oposiciones a cargos de subdelegados ${ }^{117}$ pero estas quedaron suspendidas en 1927 con la excusa de iniciarse el proceso de reunificación de los Cuerpos de Sanidad ${ }^{118}$.

Una vez acomodados los Inspectores provinciales en sus nuevos destinos según la conveniencia del Gobiemo, la estrategia sanitaria de la Dictadura, basada en la implantación de Institutos provinciales de Higiene ${ }^{119}$ con la finalidad de llevar el control de la Administración a todo el territorio nacional, y la presión de los propios Inspectores, hicieron que se les otorgara progresivamente nuevas funciones y prerrogativas sobre el resto de los funcionarios sanitarios. En primer lugar, el Reglamento provincial de Sanidad ${ }^{120}$ confirmaba todo lo legislado acerca de su organización y funciones y lo situaba como «Jefe técnico de los servicios sanitarios de la provincia y del personal adscrito a los mismos», los cuales incluían a los Institutos provinciales de Higiene. No obstante, la dirección efectiva del centro, con derecho a percibir una gratificación de la Diputación compatible con su sueldo, sólo podría ejercerla el Inspector provincial si acreditaba que ya ejercía dicho cargo en las desaparecidas brigadas sanitarias. En el caso de que la dirección técnica y efectiva del Instituto estuvieran vacantes, esta última no se debía cubrir hasta la toma de posesión del nuevo Inspector provincial, el cual tendría preferencia sobre clla si ya era jefe efectivo del Instituto provincial de procedencia. En todos los casos restantes, la dirección efectiva del centro se dotaría mediante oposición que se celebraría en Madrid ante tribunales propuestos por la Dirección General de Sanidad. Con el desempeño de la dirección efectiva de los Institutos provinciales el Inspector provincial acumulaba unos ingresos nada desdeñables en comparación con otros funcionarios de la Administración. A las dos subidas salariales consecutivas de 1919 y 1921 se sumaba la remuneración por parte de las Diputaciones de sus servicios en los Institutos de Higiene - si eran los directores efectivos - y en la Higiene de la prostitución - confirmada por el artículo 51 del Reglamento provincial - todo ello unido a los ingresos procedentes del cobro de las tarifas sanita- rias. En 1926, se calculó que los ingresos anuales medios de un Inspector provincial oscilaban alrededor de 12.000 pesetas aunque los funcionarios situados en los primeros números del escalafón las superaban claramente ${ }^{95}$.

\section{UN CUERPO UNIFICADO PARA UN ESTADO ORGÁNICO Y CENTRALISTA}

La reestructuración de la organización sanitaria de 1919 propició el inicio de la unificación al realizarse por primera vez una plantilla de los «Cuerpos facultativos de Sanidad» en la que, como ya hemos visto, aparecían las tres ramas del nuevo organigrama de la Inspección General de Sanidad, pero será con la Dictadura de Primo de Rivera cuando se lleve a efecto de una forma decidida la unificación tomando como eje la Escuela Nacional de Sanidad creada en diciembre de $1924^{121}$. En efecto, el Real Decreto que le dio vida establecía que la entrada en los Cuerpos de funcionarios médicos se haría exclusivamente a través de esta institución a la que se accedería mediante concurso-oposición a un número de plazas limitadas. Estas plazas estarían dotadas con el haber anual de 3.500 pesetas y al finalizar sus estudios, y tras una prueba aun no especificada, los alumnos ingresarían, indistintamente, en las plazas vacantes de Sanidad interior, Sanidad exterior e Instituciones sanitarias ya que la formación homogénea recibida les capacitaría para desempeñar cualquiera de dichos puestos ${ }^{122}$. Dado el primer paso, el siguiente fue unificar los emblemas y uniformes de los Cuerpos de Sanidad nacional ${ }^{123} \mathrm{y}$ las carteras de identidad de los mismos que deberían servir para «identificación y prueba de autoridad y funciones». Los funcionarios sanitarios a los que se proveyese de cartera de identidad tendrían derecho al uso de armas en actos de servicio ${ }^{124}$. La militarización de la vida político-administrativa, característica del régimen dictatorial, se reflejaba así en el ámbito sanitario.

La aprobación de las nuevas normas por las que se ingresaría en los Cuerpos de Sanidad y que tendría como consecuencia la unificación de los mismos puso en guardia a los Inspectores provinciales que muy pronto plantearon sus reivindicaciones al respecto. Ante la 
ausencia de un órgano de expresión propio José Alberto Palanca creó la revista mensual Archivos de Higiene y Sanidad Pública entre cuyos objetivos se encontraba el estar dispuesta «al perfeccionamiento de las clases sanitarias, dando a la palabra sanitario la especialización profesional que le corresponde» ${ }^{125}$. En su primer número (enero de 1925), y antes de que se promulgara el Reglamento de Sanidad provincial, Palanca lanzó unas «indicaciones muy generales» sobre reorganización sanitaria que dejaban traslucir cuales eran las aspiraciones de los Inspectores provinciales. Proponía, en primer lugar, la creación de un Cuerpo de Sanidad único del cual saliesen los destinos equivalentes a los que desempeñaban los inspectores de Sanidad interior, Sanidad exterior, Instituciones sanitarias y subdelegados. En segundo lugar, una Jefatura única en cada capital de provincia, es decir un solo jefe sanitario municipal y provincial perteneciente al «Cuerpo de Sanidad del Reino» que dependería de la Dirección General de Sanidad «con lo cual desaparecerían enojosas cuestiones de competencia y duplicidades del servicio». Por último, debería instaurarse un sistema de provisión de vacantes que permitiera emplear a cada sanitario en aquella función para la que fuera más apto y capacitado y un Reglamento que estableciera un sistema de recompensas y sanciones $^{126}$.

El aumento de protagonismo e influencia de Palanca, tanto en el Ministerio de la Gobernación como entre los propios inspectores, significaba para Francisco Murillo una preocupación para su estabilidad en el cargo $^{127}$, lo que explica las iniciativas que llevó a cabo para contrarrestar las actividades y presencia del Inspector provincial de Madrid en los medios periodísticos. Una de las primeras medidas del Director General de Sanidad, fue la creación del Boletín Técnico de la Dirección General de Sanidad ${ }^{128}$ revista con periodicidad bimensual que sustituía al Anuario que venía publicándose desde $1920^{129}$. Una de las ventajas que presentaba el Boletín técnico era su mayor flexibilidad para dar cabida a los trabajos de investigación de los técnicos sanitarios y los de procedencia extranjera de interés para la Sanidad nacional pero, sobre todo, la revista significaba la defensa a «los ataques y críticas injustificadas que el personal sanitario sufre, pacientemente, sin medios ni lugar donde exponer, en momento oportuno, las explicaciones propias del caso... Quién dice ataques dice también atropellos, abusos y vejaciones, que el nuevo Boletín no dejará pasar sin protesta, venga de donde venga ${ }^{130}{ }^{13}$. La siguiente actuación de Murillo fue una Real Orden promulgada directamente por la Presidencia del Consejo de Ministros que declaraba incompatible el cargo de Catedrático con el de Inspector provincial de Sanidad ${ }^{131}$, orden que, a pesar de que no se llegó a cumplir, no pasó desapercibida para los que se sintieron atacados como el propio Palanca ${ }^{127}$.

En octubre de este mismo año, los Inspectores provinciales se reunieron en Madrid para discutir, entre otras ponencias puramente sanitarias, el papel que debían jugar en la futura organización de los Cuerpos de Sanidad una vez iniciado el proceso de unificación ${ }^{132}$. Sus conclusiones ampliaban y clarificaban la propuesta de Palanca al reivindicar la jefatura efectiva de los Institutos provinciales de Higiene a su vez que pedían que estos centros pasaran a depender administrativamente de la Dirección General de Sanidad. Además, reclamaban autoridad para intervenir directamente en los ayuntamientos «con el fin de que no puedan distraer para otras atenciones el dinero que debe ser empleado para atenciones sanitarias» y advertían que, mientras no se suprimiera el régimen de autonomía sanitaria municipal, los Inspectores provinciales de Sanidad no se hacían responsables del estado sanitario de sus provincias respectivas. Su autoridad también pretendía llegar al ámbito privado al acordarse que «a semejanza de las Leyes sanitarias inglesas» se les permitiera penetrar en los domicilios para comprobar los delitos sanitarios y practicar desinfecciones «para garantía del bicn social».

Las conclusiones de la ponencia «Fusión de los Cuerpos sanitarios» fueron también muy clarificadoras y anunciaban las dificultades con las que contaría la creación efectiva de un Cuerpo único. Con el argumento de que se debían respetar las categorías administrativas de los funcionarios, los asambleístas entendían que no podían fusionarse los escalafones en 
tanto no se extinguiesen los tres escalafones existentes. Los funcionarios procedentes de la Escuela Nacional de Sanidad, debían, por tanto, iniciar el escalafón único $y$, hasta la extinción de los tres Cuerpos, el número uno de promoción de la Escuela debía colocarse inmediatamente después del último de los funcionarios de dichos Cuerpos. El mecanismo para la provisión de vacantes perseguía la implantación progresiva de la jefatura provincial única aunque el personal procedente de la Escuela lo tendría aun más difícil para alcanzar una plaza. La propuesta consistía en dar preferencia a los funcionarios del Cuerpo a que perteneciera la plaza y después a los funcionarios de las otras dos ramas. Si la plaza vacante no fuese reclamada por ninguno de los anteriores se amortizaría y el Inspector provincial o el Director de Sanidad marítima que quedase en funciones tomaría el nombre de «Director de Sanidad». Si por algún motivo vacase la Dirección de Sanidad se establecería un concurso con el siguiente orden de preferencia: $1^{\circ}$, los individuos del Cuerpo cuya vacante motiva la fusión; $2^{\circ}$, los del Cuerpo a que perteneciera el anterior director; $3^{\circ}$, los funcionarios de Instituciones sanitarias y $4^{\circ}$, los procedentes de la Escuela Nacional de Sanidad.

La respuesta del Ministro a las conclusiones aprobadas en la asamblea y ante la inminente incorporación a la Administración sanitaria de los alumnos de la Escuela Nacional de Sanidad, fue nombrar una Comisión que elaborase un proyecto de reorganización de plantillas y escalafones de los cuerpos sanitarios «con el doble objeto de conseguir un acoplamiento perfecto a ellos de los oficiales médicos que procedan de la Escuela Nacional de Sanidad y de permitir en lo futuro una completa unificación del personal y servicios dependientes de la Dirección General de Sanidad ${ }^{133}$. Tres meses después de nombrada la Comisión, un Real Decreto de 29 de marzo creaba el Cuerpo de Sanidad Nacional al fusionarse las tres ramas de Sanidad exterior, interior e instituciones sanitarias ${ }^{134}$. El preámbulo del Decreto Ley merece reproducirse ampliamente:

"La existencia de tres cuerpos de funcionarios de la Sanidad nacional, nacidos uno tras otro a impulsos de apremiantes necesidades durante los cuarenta años últimos, no tiene hoy razón de ser por haberse elevado la cien. cia y la práctica sanitaria a la categoría de una verdadera profesión dentro de las ciencias médicas. No conviene tampoco al interés de los servicios ni a la compenetración espiritual que debe existir entre funcionarios que persiguen el mismo fin con los mismos medios, sostener por más tiempo tres ramas distintas que parecen otros tantos cotos impenetrables y con profesores que obtuvieron sus cargos en dificil oposición con programas casi idénticos. Por eso ha sido aspiración de los sanitarios, manifestada con mayor insistencia en ocasiones recientes la fusión y unificación de las tres ramas de la Sanidad civil en un solo tronco, de manera que todos puedan servir indistintamente en los puertos y fronteras, en las provincias y en los institutos y laboratorios del Estado. Realmente creada la Escuela Nacional de Sanidad, en la que todos los admitidos estudian las mismas materias bajo el mismo plan docente, y próxima a terminar sus cursos la primera promoción que ha de cubrir las vacantes existentes, parece llegado el momento oportuno de establecer la unidad de los cuerpos sanitarios, que sin grabar ni alterar en lo más mínimo el presupuesto dará mayor flexibilidad a la organización y más eficacia a los servicios».

De acuerdo con la asamblea de Inspectores, no se unificaron los escalafones sino que se creaba uno nuevo con el nombre de Escalafón del Cuerpo de Sanidad Nacional al que pertenecerían los funcionarios procedentes de la Escuela Nacional de Sanidad al que irían sumándose por riguroso orden de antigüedad y numeración las sucesivas promociones. Al Cuerpo recién creado también pertenecerían los tres escalafones restantes hasta su extinción de manera que todo el conjunto «constituirá el Cuerpo único de Sanidad Nacional». Por el contrario, el mecanismo para cubrir las vacantes difería notablemente de las propuestas de los Inspectores y daba libertad de movimientos al Ministerio para seguir colocando a los funcionarios a su antojo. El Decreto disponía que a las vacantes no solicitadas por los funcionarios del Cuerpo correspondiente serían destinados los emplea- 
dos procedentes de la Escuela. A pesar de todo, si la plaza seguía vacante, la Dirección General de Sanidad podría sacarla a concurso entre los miembros de las tres ramas o bien por nombramiento directo conforme a «la conveniencia de los servicios». La prioridad para los miembros del escalafón unificado sería total para las plazas de nueva creación si la Dirección del Ramo no decidía provcerlas por oposición directa. Por último, la Dirección General de Sanidad «sean cualesquiera las normas de los diferentes Reglamentos orgánicos para la provisión de las vacantes» se reservaba el derecho de proponer al Ministro la negación de la instancia o petición para cubrir vacantes a cualquiera de los aspirantes «cuando su conducta anterior, con o sin formación de expediente gubernativo, le haya hecho indeseable para el desempeño del nuevo cargo». Por las mismas razones, la Dirección General podría proponer cl traslado forzoso de un funcionario, a otro puesto de igual o inferior categoría.

El contenido de este autoritario Decreto que aprovechaba la unificación de los cuerpos de Sanidad para controlar aun más las adhesiones políticas de sus funcionarios, motivó que los afectados organizaran la Primera Asamblea de Sanidad Nacional, investida de «reunión técnica» para que fuese admitida por la superioridad. La reunión se celebró en Madrid los días 25 al 30 de octubre de 1927 con una asistencia notable: 41 Inspectores de la Sanidad interior, 46 médicos de la Sanidad exterior y $28 \mathrm{del}$ Cucrpo de Instituciones sanitarias. Las conclusiones fueron bastante claras en cuanto a la defensa de sus derechos adquiridos y al carácter lesivo que tenía para ellos la nueva organización de los cucrpos sanitarios. En primer lugar, la forma de ingreso en la Escuela Nacional de Sanidad debía ser libre, su plan de estudios alargarlo hasta los dos años y el aspirante, al término de sus estudios, estaría en condiciones de tomar parte en el concursooposición de ingreso en los cuerpos de Sanidad. Para la ocupación de vacantes tendrían preferencia los miembros de la rama que vacó la plaza y en caso de quedar desierta se convocaría un concurso-oposición entre los funcionarios de las otras dos ramas, siempre con un tribunal en el que la mayoría de sus miembros pertenccieran a la referida rama que motivó la plaza vacante. Finalmente, retomaban las ambiciosas reivindicaciones de los Inspectores provinciales realizadas en anteriores reuniones como era la refundición, dentro de la Dirección General de Sanidad, de todos los servicios sanitarios dependientes de los distintos ministerios -excepto los de Sanidad Militar- y la creación de una Jefatura provincial única sobre todos los servicios sanitarios, en este caso la excepción se hacía con los correspondientes a Sanidad exterior ${ }^{135}$.

Casi simultáneamente, Palanca se expresó sobre estos problemas en un discurso dirigido a la Academia de Higiene en cuyos contenidos podemos apreciar una firme defensa del afán de los Inspectores provinciales de monopolizar la autoridad sanitaria. Sostenía Palanca que no se podía realizar una verdadera organización sanitaria sin lastimar los derechos adquiridos y quién se atreviera a mejorar la situación del momento daría «en tierra» a causa de las protestas ejercidas desde el sector que se sintiera perjudicado «... por eso yerran los que creen que una dictadura sanitaria resolvería nuestro problema». En este sentido, la jefatura provincial única no podía realizarse «repentinamente publicando una disposición en la Gaceta» porque se dañarían no sólo muchos intereses creados «sino legítimamente creados». El cambio debía realizarse paulatinamente, «buscando oportunidades allí donde el Municipio de la capital no tuviese aún nombrado su Jefe de Sanidad». Tampoco se encontraba conforme con la organización de la carrera sanitaria que debía comenzar en la inspección sanitaria municipal, seguir en la de distrito y terminar en los Cuerpos del Estado o en las grandes ciudades. Por este motivo estaba en contra de que se invistiera de autoridad a los inspectores municipales porque «la verdadera protección a un sujeto o a una colectividad no es la de concederles unas migajas, sino la de darles la ocasión de que con su trabajo, con su cultura, se rediman al mismo tiempo que con ello redimen al país». Finalmente recordaba a los inspectores municipales que tuvieran en cuenta lo que había sucedido con los Inspectores provinciales que junto con el reconocimiento de autoridad habían perdido el derecho a la inmovilidad ${ }^{136}$. 
LA CONFIGURACIÓN DE UNA ÉLITE: DE INSPECTORES PROVINCIALES A JEFES DE LA SANIDAD PROVINCIAL

La figura de Francisco Murillo en la Dirección General de Sanidad había comenzado a declinar como consecuencia del impacto negativo que causó en los medios sanitarios su nombramiento como director del Instituto Técnico de Comprobación pocos días antes de la promulgación del también conflictivo Decreto de unificación ${ }^{110}$. Se daba la circunstancia que Murillo era el propietario de un laboratorio que fabricaba sueros bioterapéuticos, productos que, además de hacer la competencia al propio Instituto, debían ser verificados por este para su autorización y venta ${ }^{137}$. No obstante, es posible que el gobierno ya pensara en el recambio de Murillo al frente de la Dirección General de Sanidad cuando le nombró Director del Instituto Técnico ya que dotó a este nuevo cargo de «la misma categoría, derecho y consideraciones que las Direcciones generales dependientes del Ministerio de la Gobernación» y con una espléndida remuneración anual de 18.000 pesetas $^{138}$. En mayo de 1928, cuando fue sustituido por Antonio Horcada Mateo (n. 1872) - Teniente Coronel de Sanidad Militar y hasta entonces Gobernador civil de la provincia de Granada - se mantuvo al frente del citado Instituto $^{139}$.

Una vez cesado Murillo, el Ministro de la Gobernación convocó una inusual reunión en Madrid con todos los Inspectores provinciales de Sanidad y con el nuevo Director General del Ramo ${ }^{140}$. A pesar de que esta reunión debía de tener un carácter meramente informativo acerca de la labor realizada por los inspectores en sus respectivas provincias es muy probable que Martínez Anido escuchara las reivindicaciones y problemas planteados por los Inspectores después de la asamblea de octubre, además de servir de primer encuentro entre estos y el nuevo Director General. En consecuencia, en junio de ese mismo año, se prosiguió con el proceso de unificación fusionando las distintas plantillas mediante un Real Decreto-Ley que, no obstante, respetaba los Reglamentos y escalafones para cada una de las tres ramas ${ }^{\mathrm{i} 11}$. En su preámbulo se aclaraba que la unificación de plantillas era la única manera de que tuviera efectividad «el aprovechamiento de las aptitudes de cada individuo para el desempeño de la función que se le encomiende». Un mes después, la Gaceta dio cuenta de la confirmación en sus cargos de todos los funcionarios que formaban el Cuerpo de Sanidad Nacional ${ }^{142}$.

En el periodo de Horcada, se completó el Reglamento de los Inspectores provinciales de Sanidad con el objetivo de acomodarlo a la Ley de funcionarios y empleados públicos de julio de 1918 una vez ordenado el escalafón por categorías administrativas $\mathrm{y}$, al mismo tiempo, asegurar la permanencia de un mínimo de tiempo del Inspector provincial en su plaza antes de solicitar permutas y excedencias voluntarias, exigencias que no estaban comprendidas en el Reglamento de 1920 y que había permitido que muchos de los excedentes apenas estuviesen unos días en su cargo ${ }^{143}$. De esta forma, se impuso un mínimo de dos años en sus plazas respectivas para que los Inspectores pudiesen solicitar permutas así como un año de permanencia en la misma categoría y clase para la solicitud de excedencia voluntaria ${ }^{144}$. También, en estos dos últimos años de la Dictadura, el gobierno aumentó el grado de implicación de las Diputaciones provinciales en el mantenimiento de las Inspecciones provinciales, independientemente de su relación con los Institutos provinciales de Higiene, al mismo tiempo que se dotaba de mayor autoridad a los Inspectores provinciales de Sanidad. En efecto, en diciembre de 1928 y tras un dictamen de la Dirección General de Administración, se confirmaba la obligación de las Diputaciones provinciales de facilitar a las inspecciones provinciales un auxiliar administrativo y un ordenanza «para atender a las necesidades del servicion ${ }^{145}$. Simultáneamente, el gobierno otorgó a los Inspectores provinciales la facultad de imponer multas hasta de quinientas pesetas tanto a funcionarios como a las corporaciones provinciales y municipales si aquellos y estas incurrían en delitos sanitarios $^{146}$. En 1929, se volvió a gravar las arcas de los gobiernos provinciales al publicarse en la Gaceta una disposición que obligaba a las Diputaciones al pago de los gastos ocasionados por los desplazamientos de los Inspectores 
provinciales a los pueblos de su jurisdicción ${ }^{147}$. Previamente, una Real Orden había establecido que estos funcionarios visitaran todos los Ayuntamientos de la provincia, en un plazo máximo de tres años, para vigilar el cumplimiento de las normas sanitarias ${ }^{148}$.

A pesar de todas las prebendas concedidas a los Inspectores provinciales, estos no estaban dispuestos a correr el riesgo de perder sus derechos adquiridos tras la unificación lo que motivó que se nombrase, en noviembre de 1928, una Comisión encargada de revisar toda la legislación sobre organización de Cuerpos y servicios «que han dejado de ser aptas para regir el nuevo organismo y satisfacer las necesidades sanitarias actuales ${ }^{149}$. Este proyecto de reorganización sanitaria tropezó con la crisis de la Dictadura pero el mismo día en que el General Berenguer se hacía cargo del Gobierno, una Real Orden firmada por el nuevo Ministro de la Gobernación, el General Enrique Marzo Balaguer, daba la razón a los Inspectores provinciales al aclarar que no podían considerarse equivalentes los derechos adquiridos por los distintos funcionarios juzgando únicamente por la categoría que tenía cada uno de ellos. Se argumentaba que a los Inspectores provinciales se les había exigido el título de doctor y ocho años de ejercicio profesional, requisitos que no tuvieron que cumplir las otras dos ramas y, por lo tanto, los Inspectores aparecían colocados en categoría administrativa «más baja que las que tienen los de edad equivalente de las Ramas afines». Por tanto, el legislador confirmaba que no se podía constituir un sólo escalafón «ínterin existan los derechos adquiridos por cada uno de los funcionarios de la Rama respectiva» por lo que era preciso mantener la separación debida en la ordenación de los diferentes funcionarios que integraban el Cuerpo de Sanidad ${ }^{150}$.

Esta Real Orden que defendía a ultranza los derechos de los Inspectores provinciales sólo fue el preámbulo de una serie de disposiciones legislativas inspiradas por José Alberto Palanca, nombrado nucvo Director Gencral de Sanidad en febrero de $1930^{151}$, y destinadas a reponer y salvaguardar los intereses de los funcionarios sanitarios, sobre todo de los Inspectores provinciales. La primera medida fue dejar sin efecto el Real Decreto de unificación del Cuerpo de Sanidad Nacional así como las polémicas disposiciones de septiembre de 1923 sobre incompatibilidades y traslados forzosos de los Inspectores provinciales de Sanidad $^{152}$. Todo ello acompañado de un nuevo Reglamento unificado del personal al servicio de la Dirección General del ramo que, paradójicamente, hacía más profunda la separación de sus miembros ${ }^{153}$.

Según este Reglamento, el Cuerpo de Sanidad Nacional quedaba constituido por los funcionarios pertenecientes a los escalafones de las tres ramas sanitarias y por los procedentes de las dos primeras promociones de la Escuela Nacional de Sanidad. Todos ellos formarían un escalafón único, por categorías y clases, pero conservando la autonomía de las distintas Ramas. El orden preferente lo marcaba la antigüedad en cada Rama y en caso de igualdad, la antiguiedad absoluta en Sanidad. La categoría y clase de cada funcionario médico vendría dada por su situación en el escalafón y en ninguna medida por la plaza desempeñada $y$, en consecuencia, las vacantes ocurridas en la plantilla del Cuerpo se cubrirían por rigurosa antigüedad del funcionario de la misma Rama del que ocasionó la vacante con el consecuente corrimiento de escalas dentro de la Rama correspondiente.

Otraide las novedades fue el mecanismo para la provisión de cargos y destinos vacantes mediante el cual, el Cuerpo de Sanidad Nacional quedaba dividido en tres grupos: el «Inspector», que comprendía a los Inspectores provinciales de Sanidad y a los Directores y Subdirectores de Sanidad de puertos y fronteras; el «Grupo de Laboratorios», integrado por el Instituto Nacional de Higiene de Alfonso XIII y las plazas dependientes de la Dirección General de Sanidad; y, por último, el «Grupo clínico» que constaba del Hospital del Rey, Sanatorios, Dispensarios, Enfermerías y Preventorios dependientes de la Dirección General, así como los Hospitales para niños y la Escuela de Puericultura. Cada grupo tenía su orden de preferencia para cubrir las vacantes. Para el Grupo Inspector tendrían preferencia los médicos ingresados por oposición directa a los antiguos cuerpos de Inspectores y Sanidad 
exterior, según la Rama en la que radicara la vacante; a continuación los médicos procedentes de otras ramas o de las dos primeras promociones de la Escuela Nacional de Sanidad que hubiesen prestado servicio en cualquiera de estas dos ramas. Por último, el resto de los funcionarios del Cuerpo, incluidos los que ingresaran con posterioridad. Para cubrir las Inspecciones provinciales de Madrid y Barcelona se recurrió de nuevo a un criterio de discrecionalidad pero, ahora, sería mediante un concurso especial de méritos entre los miembros del Grupo Inspector que reunieran, entre otros, los requisitos de ser doctores y llevar más de diez años efectivos al servicio de la Sanidad. Los turnos para estos cargos debían seguir también el mismo criterio que para el resto del Grupo Inspector, como hemos visto anteriormente.

Para el ingreso en el Cuerpo, el Reglamento recogía las reivindicaciones planteadas por los funcionarios sanitarios y volvía a establecer el concurso-oposición entre los aspirantes. Estos últimos debían estar en posesión del Título de Oficial Médico sanitario, expedido por la Escuela Nacional de Sanidad tras cursar en ella el curso regular. El ingreso se realizaría de forma directa y separada a cada uno de los grupos Inspector, Clínico y de Laboratorio con programa y Tribunal distinto para cada uno de ellos. Los miembros que ingresaran por este último mecanismo sólo podrían participar en aquellos concursos cuyas plazas fueran del grupo al que ingresaron directamente. El resto de las disposiciones no variaban sustancialmente lo legislado con anterioridad, tan sólo podemos destacar la falta de exigencia de un mínimo de tiempo en el cargo para la concesión de excedencias y permutas, estas últimas limitadas «a casos excepcionales». Además, se confirmaba la inclusión de los funcionarios del Cuerpo en los del Estado que «por la índole especial del servicio que les está encomendado» precisaban licencia de uso de armas.

Bajo la República, una vez cesado con toda celeridad José Alberto Palanca como Director General de Sanidad ${ }^{154}$, el nuevo Director General, Marcelino Pascua firmaba una circular en la Gaceta modificando los emblemas de la Sanidad Nacional y pidiendo a los funcionarios que remitiesen sus carteras de identidad para ser sustituidas por las adoptadas oficialmente $^{155,156 .}$ El primer paso dado por Marcelino Pascua, en su afán por que los miembros del Cuerpo estuviesen dedicados integramente a sus oficios de sanitarios, fue la prohibición del ejercicio de la medicina privada a aquellos Inspectores provinciales que percibieran gratificaciones como directores de los Institutos provinciales de Higiene y por la Jefatura de los servicios antivenéreos. También se prohibía la acumulación de cargos que no fuesen reconocidos por la Dirección General de Sanidad como anejos a las funciones sanitarias de los Inspectores provinciales ${ }^{157}$. El mes siguiente se ampliaba esta prohibición al Inspector General de Sanidad exterior y a los directores de Sanidad de los puertos de Barcelona, Valencia, Las Palmas, Santa Cruz de Tenerife, Vigo y Bilbao y se fijaba también la incompatibilidad de todos los cargos de Sanidad exterior con el de subdelegado de Medicina, Jefe de Sección de los Institutos provinciales de Higiene y epidemiólogo de los mismos ${ }^{158}$.

Otras de las medidas tomadas por el gobierno presidido por Azaña, en diciembre de ese mismo año, fue declarar revisables todos los nombramientos del personal dependiente de la Dirección General de Sanidad cuyos cargos no hubiesen sido obtenidos por concurso $\mathrm{u}$ oposición ${ }^{159}$. La lista, publicada ese mismo mes $^{160}$, afectaba a un total de 98 personas, casi todas pertenecientes al profesorado de la Escuela Nacional de Sanidad (33) y a las plantillas de los dispensarios y sanatorios antituberculosos oficiales (51); estos últimos centros habían pasado a depender de la Dirección General del Ramo unos meses antes. Para la provisión definitiva de estos cargos, el Ministerio de la Gobernación se comprometía a convocar los concursos u oposiciones libres necesarias, mientras tanto, el personal afectado seguiría provisionalmente en sus puestos. En los meses posteriores fueron apareciendo en la Gaceta las distintas convocatorias para cubrir parte de las vacantes antes reseñadas y sus respectivas resoluciones lo que amplió el número de personas pertenecientes al Cuerpo de Sanidad Nacional. A estas habrá que sumar las incorporaciones al Cuerpo de los Jefes de los 
Centros secundarios de Higiene rural, asimilados al Grupo Inspector y con categoría de Jefes de Negociado de tercera clase. La primera convocatoria para 26 plazas de este tipo se hizo en abril de 1932 con la exigencia a los aspirantes de poseer el Título de Oficial sanitario expedido por la Escuela Nacional de Sanidad u ocupar cargos, mediante concurso u oposición, en los Institutos provinciales de Higiene ${ }^{161}$.

La tendencia expansiva del Cuerpo Nacional de Sanidad se vio afectada por la crisis presupuestaría de agosto de 1932, que motivó la congelación de todos los concursos y oposiciones que implicaran aumento de plantilla, así como la prohibición expresa de modificar los escalafones del funcionariado. Por este motivo, una Ley de 14 de septiembre de 1932 autorizaba al Ministro de la Gobernación, Santiago Casares Quiroga, a modificar los servicios dependientes de su Ministerio «en la medida que las necesidades exijan» ${ }^{162}$. Este mecanismo fue el que permitió la dotación de parte de las jefaturas de los recién creados Centros secundarios de Higiene rural las cuales se cubrieron con personal que estaba ocupando plazas de Directores de Sanidad de puertos y fronteras ${ }^{163}$. El traslado de funcionarios de la Sanidad exterior a la interior era coherente con la importancia otorgada a los Centros secundarios de Higiene rural y a la autoridad que se les confirió a sus jefes, cargos técnicos con funciones delegadas del Inspector provincial con la facultad de dirigir todas las instituciones sanitarias radicadas en su zona. En esta misma Orden se disponía que tres de los directores de Sanidad exterior afectados pasasen a las órdenes de los Inspectores provinciales de Cáceres, Albacete y Alicante, inaugurando de esta forma la figura de Subinspector provincial de Sanidad, cargo que se dotó sólo en algunas provincias $^{164}$.

Esta nueva configuración sanitaria, volcada hacia la intervención médico-social en las zonas rurales, hizo más poderosa la figura del Inspector provincial que, todavía bajo el mandato de Marcelino Pascua, amplió su área de influencia sobre parte del personal y recursos bajo la jurisdicción de la Sanidad exterior. En efecto, una Orden de febrero de 1933 establecía la subordinación de 16 estaciones sani- tarias al Inspector provincial de su zona el cual podría disponer de sus dotaciones «en cuanto afecte a materias propias de la Sanidad interior», considerándose a los directores de estas estaciones como delegados de aquellos ${ }^{165}$. Posteriormente, la Ley de coordinación sanitaria asignaba a los Inspectores provinciales la función de Secretarios generales de las Juntas administrativas de las Mancomunidades de Municipios con la tarea de elaborar y presentar un proyecto de presupuestos para los servicios sanitarios $^{166}$.

Otra de las funciones que pasaron a manos del Inspector provincial en estos años fue la tarea de llevar el registro de los títulos de los médicos que ejercían en su provincia. Esta nueva función, que ahora debía desempeñar el Inspector provincial gratuitamente, fue la consecuencia de un Decreto que declaraba a extinguir el Cuerpo de Subdelegados. En efecto, en septiembre de 1933, el régimen republicano resolvió de manera definitiva la situación de una organización «tan arcaica como la de Subdelegados» por su falta de armonización «con las modernas orientaciones sanitarias» ${ }^{167}$. El preámbulo del Decreto reconocía también las «legítimas aspiraciones» de los Ayuntamientos a prescindir de una figura que, pese a desarrollar funciones de índole municipal, escapaba a su jurisdicción. El resto de los servicios de las Subdelegaciones, a medida que fuesen amortizadas, se transferirian a los Inspectores Municipales de Sanidad los cuales pasarían a recibir los correspondientes emolumentos.

El Reglamento del personal sanitario promulgado en 1930 bajo la inspiración de $\mathrm{Pa}$ lanca establecía una separación entre los funcionarios sanitarios clínicos y los meramente dedicados a tareas de inspección y profilaxis pública, pero no tuvo un reflejo real en las plantillas y escalafón del Cuerpo que siguió inalterable durante el tiempo en que estuvo en el poder la conjunción republicano-socialista. En este periodo, la incorporación de la Beneficencia general al Ministerio de la Gobernación, el desarrollo de las luchas sanitarias dentro de la Dirección General de Sanidad y la creación efectiva de los Centros secundarios de Higiene rural confirmaba la 
tendencia de la coalición de centro-izquierda a financiar con fondos públicos la totalidad de la asistencia sanitaria de las clases sociales menos favorecidas ${ }^{168}$. Estas actuaciones contrastaban claramente con la opinión de los médicos libres que denunciaron en repetidas ocasiones la competencia desleal que significaba la asistencia clínica en los centros profilácticos públicos debido a que, en estos centros, no se exigía el certificado de pobreza para ser atendido ${ }^{169,} 170$.

Una vez en el poder, desde diciembre de 1933, los gobiernos de la coalición radicalcedista desplegaron una estrategia encaminada a contrarrestar las medidas tomadas por sus predecesores, lo que incidió en la organización sanitaria y en la de sus funcionarios. En primer lugar el traspaso de la Subsecretaría de Sanidad y Beneficencia del Ministerio de la Gobernación al de Trabajo, que pasó a denominarse Ministerio de Trabajo, Sanidad y Previsión ${ }^{171}$, buscaba una salida para la financiación de la Sanidad con el desarrollo del seguro obligatorio de enfermedad. Paralelamente, las distintas reformas del organigrama sanitario hicieron especial hincapié en separar las funciones de profilaxis y asistencia públicas, sobre todo desde octubre de 1934, fecha en que el Ministerio de Trabajo, Sanidad y Previsión fue puesto en manos del miembro de la CEDA, José Oriol Anguera.

Junto a la reestructuración sufrida por la Dirección General de Sanidad en mayo de 1935, con la unificación a todos los efectos de las distintas ramas del Cuerpo de Sanidad Nacional y el cambio de nombre de las Inspecciones provinciales por el de Jefatu$\operatorname{ras}^{172,173}$, una serie de mandatos generales ${ }^{174}$, ${ }^{175}$ fue aprovechada para separar del Cuerpo de Sanidad Nacional los cargos con funciones clínicas y ahondar, de esta forma, su separación con la vertiente profiláctica y técnica de la Dirección General de Sanidad. Esta propuesta ya había sido realizada por el Inspector General de Instituciones sanitarias, Víctor María Cortezo, en su discurso de recepción en la Academia Nacional de Medicina en abril de 1935. Pedía este funcionario que se fusionara el Cuerpo de la Beneficencia general con los médicos que realizaran «análogas funciones» dentro de la Sanidad Nacional debido a que, en la lucha contra las enfermedades que más preocupaban a la sociedad era muy difícil deslindar hasta dónde debía llegar la intervención del sanitario y dónde debería comenzar la del clínico $^{176,81}$.

Seis meses después y una vez reguladas las consultas públicas gratuitas para impedir que fuesen atendidos enfermos con recursos suficientes $^{169}$, se llevó a cabo la división en varios grupos del personal de los servicios de Sanidad y Beneficencia mediante un Decreto de la Presidencia del Consejo de Ministros ${ }^{177}$. En el primer grupo figuraba el Cuerpo Médico de Sanidad Nacional, al que corresponderían «las funciones ejecutivas, inspectoras, de educación y autoridad sanitarias y la dirección de los Centros de enseñanza e investigación». A continuación, y en el grupo segundo, los médicos especialistas y clínicos dependientes de los centros estatales de Sanidad y Beneficencia. En tercer lugar, los médicos adscritos a las luchas sanitarias y, por último, el grupo cuarto lo configurarían el personal facultativo y profesional no médico (veterinarios, farmacéuticos, ingenieros y similares). Transitoriamente, las plazas clínicas desempeñadas por médicos del Cuerpo de Sanidad Nacional serían dadas de baja en la plantilla del Cuerpo cuando estas quedasen vacantes. En este mismo Decreto se establecía la incompatibilidad con el libre ejercicio de la profesión a todos los altos cargos de la Dirección General del ramo, se confirmaba dicha incompatibilidad para los Jefes provinciales de Sanidad (antes Inspectores) y Directores de Centros secundarios de Higiene rural y se ampliaba a otros cargos específicos.

El Reglamento Orgánico del Cuerpo Nacional de Sanidad, aprobado en diciembre de $1935^{178}$, confirmaba la pertenencia al mismo a todos los que figuraban en el escalafón realizado en diciembre de $1934^{179}$ manteniendo su categoría y clase con independencia de las plazas desempeñadas. La unificación de las tres ramas «a todos los efectos» legislada en mayo fue matizada para no dañar los derechos adquiridos de los funcionarios pero sí se simplificó el mecanismo para cubrir las vacantes. En la plantilla del Cuerpo, las vacantes se cubrirían por rigurosa antigüedad entre los 
funcionarios de la misma rama pero, una vez agotado el grupo de estos funcionarios después del corrimiento de las escalas, la resulta se adjudicaría al funcionario de la categoría y clase inmediata inferior con mayor antiguiedad absoluta en Sanidad, cualquiera que fuese su procedencia. La provisión de cargos vacantes correspondientes a Jefaturas provinciales, Direcciones y Subdirecciones de Sanidad exterior y Jefaturas de Centros comarcales de Higiene rural se realizaría por concurso voluntario de rigurosa antigüedad pero con el siguiente orden de preferencia: en primer lugar los médicos ingresados directamente en el Cuerpo extinguido (Sanidad interior o exterior) a que la vacante correspondiese; en segundo lugar los médicos del Cuerpo de las dos primeras promociones de la Escuela Nacional de Sanidad y, por último, los demás médicos del Cuerpo sin distinción de procedencia.

Para cl ingreso en el Cuerpo se volvía a la formula original de «médicos alumnos oficiales» del Instituto Nacional de Sanidad mediante oposición libre. Esta institución asumió las funciones de la Escuela Nacional de Sanidad cuando esta fue extinguida por Decreto de 1/10/1934. Después del curso oficial, los alumnos pasarían a ocupar puesto en el escalafón del Cuerpo, según el orden de prelación establecido tras un examen de aptitud. En caso de que no se superara esta prueba el alumno debía repetir el curso. El resto del articulado confirmaba la legislación anterior sobre incompatibilidades y recogía la plantilla del Cuerpo una vez ajustada a la nueva reglamentación y disposiciones anteriores.

Pueden considerarse a los años durante los cuales imperó el régimen republicano como el periodo en el que el Cuerpo Nacional de Sanidad se consolidó definitivamente tanto en su vertiente administrativa como doctrinal. Durante este tiempo, los funcionarios sanitarios se dotaron con todos los elementos necesarios para ser considerados una profesión especializada dentro de la Medicina social. Este proceso, paralelo con el de otras ramas especializadas en esta materia, culminaría con la cclcbración del Primer Congreso Nacional de Sanidad en mayo de $1934^{180}$. Previamente, el Boletín Técnico de la Dirección General de Sanidad, se había con- vertido en la Revista de Sanidad e Higiene Pública (enero de 1932) bajo la responsabilidad de la Comisión Permanente de Investigaciones Sanitarias creada por Decreto de 13/10/1931. Asimismo, el título de Oficial Sanitario, expedido por la Escuela Nacional de Sanidad y requisito imprescindible para el ingreso en el Cuerpo, fue otorgado a todos los miembros del mismo en diciembre de $1933^{181}$.

\section{CONTINUIDAD EN EL CUERPO Y RELEGACIÓN DE LA ACTIVIDAD «SANITARIA» DURANTE EL PRIMER FRANQUISMO}

Una vez terminada la Guerra Civil, la continuidad del Cuerpo Nacional de Sanidad se vio favorecida por el reparto de poderes entre las distintas facciones del régimen franquis$\operatorname{ta}^{182}$. En efecto, de haberse llevado a cabo las pretensiones de Falange de seguir manteniendo unidas la Sanidad y la Previsión bajo su control en un sólo Ministerio hubiera puesto en peligro la existencia del Cuerpo sanitario, cuyos miembros eran calificados de «izquierdistas» ${ }^{183}$. Según el testimonio de Juan Bosch Marín (n. 1906) la Falange, tras la guerra civil, intentó la «politización total» del Cuerpo de Sanidad Nacional, y la separación de todo su personal ${ }^{184}$. En mayo de 1941, con el cese de Serrano Suñer y el nombramiento del General Valentín Galarza como Ministro de Gobernación y del falangista Girón de Velasco como Ministro de Trabajo se culminaba el reparto de competencias, quedando definitivamente la Sanidad Nacional fuera del ámbito de poder de la Falange. La Dirección General de Sanidad, reincorporada al Ministerio de la Gobernación en el gobierno de 1939, fue adjudicada a José Palanca relacionado con los círculos militares y católicos con afinidades monárquicas. El cargo de Director General de Sanidad, que ya ocupaba Palanca de forma interina desde el gobierno de Burgos, lo desempeñaría hasta 1957, año en el que fue sustituido por Jesús García Orcoyen (n. 1903).

Esta separación política marcó el desarrollo de la Sanidad española al permitir la coexistencia de dos organismos paralelos (la Sanidad Nacional y el Seguro Obligatorio de 
Enfermedad puesto en marcha por el Ministerio de Trabajo en 1944) que, entre otras consecuencias, favoreció la duplicación de servicios e instalaciones sanitarias sin establecerse ningún tipo de coordinación entre ellas ${ }^{182}$. Ni la Dirección General de Sanidad intervino en la instauración del Seguro, ni el Ministerio de Trabajo respetó la legislación sobre el mismo incluida en la Ley de Bases de Sanidad Nacional, promulgada en noviembre de $1944^{185}$. No es ajeno a esta problemática el hecho de que la mayoría de los funcionarios sanitarios se encontraran disponibles al término de la guerra civil y superaran además el proceso de depuración política de empleados públicos que puso en marcha la dictadura franquista. En efecto, si comparamos el escalafón del Cuerpo Nacional de Sanidad de 1935 con el de 1942 podemos observar que, de los 189 miembros del Cuerpo que aparecen en el escalafón de 1935 solo faltan 37, lo que significa que el 80 por ciento de los funcionarios permanecieron en el Cuerpo después de la purga franquista. Si además, tenemos en cuenta a los 31 médicos que aprobaron las oposiciones de ingreso en el Cuerpo en mayo de 1936, de los cuales tres no aparecen en el escalafón de 1942, el porcentaje se eleva al 82 por ciento.

A pesar que la organización del Cuerpo no sufrió grandes modificaciones durante los años cuarenta tuvo que ajustarse, claro está, a las normas generales emanadas del nuevo poder establecido. En primer lugar, la legislación sobre la provisión de plazas de índole médicosanitario declaraba como «interinas» todas aquellas provistas con posterioridad al $18 \mathrm{de}$ julio de 1936 y salvaguardaba las disposiciones sobre derechos de excombatientes, mutilados y excautivos víctimas de la guerra a ocupar una parte de aquella ${ }^{5186}$. Además, los candidatos a estas plazas debian presentar «una exposición o declaración jurada de todas las particularidades de su historia científica y profesional, social y política» y se pedía a los distintos organismos estatales que, al establecerse el límite de edad en los concursos y oposiciones, se tuviera en cuenta «la obligación primordial de facilitar el acceso a la oposición de los excombatientes y demás personas a quienes la guerra detuvo e impidió el normal desenvolvimiento de sus actividades profesio- nalesw ${ }^{187}$. En cuanto a las normas concretas bajo las cuales debía regirse el Cuerpo de Sanidad Nacional, siguió vigente, hasta 1951, el Reglamento del Personal Sanitario de 8 de julio de 1930, promulgado bajo el primer mandato de Palanca. Tan solo se incluyó en el mismo la autorización al Ministerio de la Gobernación y a la Dirección General de Sanidad para alterar el turno de antiguiedad en la provisión de destinos «según lo exijan las sanciones por depuración política ${ }^{188}$.

En consecuencia, la primera - $-\mathrm{y}$ única en los años cuarenta-convocatoria para cubrir 20 plazas vacantes de Jefe de Negociado de Tercera clase ${ }^{189}$, en 1941, reservó una parte de ellas a excombatiente, excautivos y mutilados de guerra. Para poder optar al concurso-oposición, los candidatos, doctores o licenciados en medicina, no debían de superar los cincuenta años de edad y presentar un certificado negativo del Registro Central de Penados y Rebeldes. Para la valoración de méritos, el candidato debía presentar «cuantos certificados estime oportunos para acreditar su adhesión al Glorioso Movimiento Nacional y los méritos y servicios de índole sanitaria que desee alegar en el concurso». Además, la mitad de las plazas debían adjudicarse a los candidatos que estuvieran en posesión del título de Oficial sanitario. Después de la prueba se resolvió el ingreso en el Cuerpo de nueve oficiales sanitarios, entre los que se encontraban un excombatiente $y$ un excautivo, y once médicos sin el título de los cuales cinco eran excombatientes ${ }^{190,191}$. Estos últimos debían realizar un curso de la Escuela Nacional de Sanidad para obtener un número de orden definitivo en el Escalafón del Cuerpo ${ }^{192}$.

El aislamiento y abandono al que estaba sometido el Cuerpo de Sanidad Nacional fue puesto de manifiesto en la ponencia oficial de la Primera Reunión que los sanitarios efectuaron en mayo de 1943 en la que, a través de un largo lamento, expusieron la situación en la que se encontraban ${ }^{193}$. En primer lugar, se vieron en la necesidad de justificar su trabajo ante la descalificación realizada por «personas de relevante capacitación en otras disciplinas (y lo que es más doloroso, en boca de médicos prestigiosos)» cuando se les consideraba como los burócratas de la Medicina, «y al decir esto 
ponen en la frase un dejo de marcada ironía». Achacaban este mal al apartamiento mantenido por los miembros del Cuerpo del ejercicio privado de la profesión, «conducta de renunciación y sacrificio» que paradójicamente no solo repercutía en sus economías privadas sino, que era «pretexto para que se discuta y combata al Cuerpo Médico de Sanidad Nacional». También se lamentaban que su prestigio no era reconocido por la superioridad debido a que, mientras las Jefaturas provinciales se veían sometidas a todo tipo de injerencias, a ellos se les negaba la representación en otros organismos relacionados directamente con la Sanidad y, en los casos en la que existía, se reducía a un sólo miembro «la misma de otros Cuerpos y Servicios especializados en actividades clínicas o parasanitarias». Además, mientras se trataba debidamente a los demás Jefes de dependencias provinciales, los «de Sanidad quedan ordinariamente en situación de marcado desaire».

Por último, abordaron el problema de la situación económica en la que se encontraban los miembros del Cuerpo. Este tema nunca había sido discutido en las anteriores reuniones de los sanitarios, como ellos mismos recordaban, pero «las cosas han llegado a límites tales, que ya no es posible silenciar la cuestión». En la ponencia estudiaron las remuneraciones de los miembros de distintos Cuerpos especiales de la Administración, evidenciando la «humillante inferioridad» de sus haberes incluso a los de Cuerpos de inferior categoría. Entre las conclusiones aprobadas por la reunión se encontraban, además de la solución a los problemas planteados, que se revisara y refundiera toda la legislación sanitaria «en un corto número de textos legales» con la consideración de que «la Sanidad es una función primordial, ineludible e indeclinable del Estado». Pedían también que se promulgara un nuevo Reglamento del Cuerpo en el que se señalasen las funciones, dẹberes, atribuciones, jerarquía, derechos y responsabilidades de los funcionarios sanitarios y que se pusieran en vigor los Tribunales de Honor del Cuerpo para elevar el prestigio del mismo. Por último, estimaban imprescindible la creación de la $\mathrm{Mu}$ tualidad de funcionarios de la Dirección General de Sanidad.
Un año después, y coincidiendo con la puesta en marcha del Seguro Obligatorio de Enfermedad por parte del Ministerio de Trabajo, la Ley de Bases de Sanidad Nacional se limitó a reconocer la existencia del Cuerpo como «el encargado de llevar a la práctica la labor que realice directamente el Ministerio de la Gobernación» en materia sanitaria y aclaraba que se respetaría siempre «hasta su extinción» los derechos reconocidos a las tres ramas sanitarias de origen. Para el ingreso en el Cuerpo, que sólo se verificaría por oposición, se estipulaba la reserva de turnos especiales a los médicos que durante cinco años, como mínimo, y en propiedad, hubiesen desempeñado cargos sanitarios especiales en instituciones públicas. Asimismo, se establecía que los facultativos especializados al servicio de la Sanidad Nacional, pero ajenos al Cuerpo de Médicos de la misma, se constituyesen en escalafones cuando su número lo permitiese. Finalmente, se establecía la incompatibilidad de Médico del Cuerpo de Sanidad Nacional con el de Médico Especialista al servicio de la misma. El Reglamento del personal de la Dirección General de Sanidad, que finalmente se aprobó en 1951, no incorporó más novedades que las señaladas en la Ley anterior salvo el establecimiento de los Tribunales de Honor tal y como habian pedido los sanitarios en su reunión de $1943^{194}$.

En la segunda mitad del bienio, no sólo no se aumentó la dotación cconómica a los miembros del Cuerpo sino que las vacantes que se produjeron en el mismo no se cubrieron, fenómeno que contrastaba con el desarrollo que estaban tomando otros servicios dependientes de la Dirección General de Sanidad como el de Higiene infantil o el propio Patronato Nacional Antituberculoso $^{182}$. Sin embargo, el principal problema con el que chocó la Sanidad oficial al final del decenio fue el imparable desarrollo que estaba tomando el Seguro Obligatorio de Enfermedad, sobre todo cuando se pusieron en marcha las especialidades en 1948.

Este problema monopolizó la ponencia general de la Segunda Reunión Nacional de Sanitarios Españoles celebrada en Barcelona en abril de $1947^{195}$. En esta reunión se puso de manifiesto la total descoordinación entre la 
Sanidad Nacional y el Seguro de Enfermedad que limitaba su actuación a la medicina curativa sin atender los dictados sanitario-sociales que el progreso del país necesitaba. La solución no podía ser otra que la centralización de todos los servicios sanitarios en un sólo «órgano rector» pues «lo mismo que la Defensa nacional requiere unidad de mando, y la Justicia unidad de criterio, la Sanidad apetece unidad de acción» lo que evitaría, además, una innecesaria duplicidad de servicios y de gastos públicos. Este órgano central, debía hacerse cargo de todos los sectores de la Administración pública de los que dependía «indirectamente» el estado sanitario del país. En las provincias debía ser la autoridad delegada de este organismo el que asumiera la jefatura de todos los servicios de carácter sanitario. Mientras tanto, se hacía indispensable la coordinación entre los centros estatales y los organismos «paraestatales», en clara referencia al Seguro Obligatorio de Enfermedad.

El impacto que tuvo el Seguro Obligatorio de Enfermedad sobre los médicos que trabajaban para la Dirección General de Sanidad se puede observar en la promulgación de la Ley de 13 de julio de 1950 (Boletín Oficial 14/7/1950) por la que se constituían dos escalas de Médicos Especialistas al Servicio de la Sanidad Nacional, la primera con 66 plazas retribuidas mediante sueldo y la segunda con 155 plazas retribuidas con gratificaciones, lo que permitía a los médros que ocuparan estas últimas simultanear su trabajo público con el de especialista del Seguro.

\section{BIBLIOGRAFÍA}

1. Cf. Beltrán Villalva M. La Administración. En: Carr R, coordinador. La época de Franco (1939-1975). Política. Ejército. Iglesia. Economía y administración. Madrid: Espasa Calpe; 1995. p. 557-637.

2. Ley de Sanidad. El Siglo Médico 1855; 3 : 386-89.

3. Gaceta de Madrid. Prcámbulo RD 16/11/1886. GM 17/11/1886.

4. Sobrino F. Sanidad de puertos. El Siglo Médico 1874; $21: 543$.
5. R. V. Nuestra sanidad marítima. El Siglo Médico 1874; 21: 322-4.

6. Carlán D [Cortezo, C. $\mathrm{M}^{\mathrm{a}}$ ]. Plantillas de Sanidad Marítima. El Siglo Médico 1874; 21: 179.

7. Carlán D. Directores de Sanidad Marítima. El Siglo Médico 1874; $21: 417$.

8. El movimiento continuo. El Siglo Médico $1874 ; 21: 415$.

9. RO 14/10/1879. El Siglo Médico 1879; 26: $667-8$.

10. Gaceta de Madrid. RD 16/11/1886. GM $17 / 11 / 1886$.

11. Cf. Fernández García A. Introducción. Atraso y modernización en la España liberal (18341900). En: Fernández García A, coordinador. Los fundamentos de la España liberal (18341900). La sociedad, la economía y las formas de vida. Madrid: Espasa Calpe; 1997. p. 11-48.

12. Fernández García A, Rueda Laffond JC. La sociedad (1): Los grupos sociales. En: Fernández García $\mathrm{A}$, coordinador. Los fundamentos de la España liberal (1834-1900). La sociedad, la economía y las formas de vida. Madrid: Espasa Calpe; 1997. p. 151.

13. Comín Comín F. El sector público y la economía: Hacienda, regulación y proteccionismo en la España liberal. En: Fernández García A, coordinador. Los fundamentos de la España liberal (1834-1900). La sociedad, la economía y las formas de vida. Madrid: Espasa Calpe; 1997. p. 418-9 y 440.

14. Gaceta de Madrid. RD 16/11/1886. GM $17 / 11 / 1886$

15. Reglamento Orgánico provisional de Sanidad Marítima. El Siglo Médico 1887; 34: 440-6, $478-9,506-7,526-7,542-3,574-5,589-90$, $622-3,652-4,666-8,685-8$ y 718 .

16. Villacorta Baños F. Profesionales y burócratas. Estado y poder corporativo en la España del siglo XX, 1890-1923. Madrid: Siglo XXI; 1989. p. 45, 153-61, 414, 427, 434.

17. Pulido Fernández A. Sanidad Pública en España y ministerio social de las clases médicas. Madrid: Tip. E. Teodoro; 1902. p. 65, 66, 68,64 .

18. Un Director de cuarta. Sanidad Marítima. El Siglo Médico 1890; 37: 409-10.

19. Gaceta de Madrid. RD 25/7/1892. GM 29/7/1892. 
20. Gaceta de Madrid. RD 13/8/1899. GM 17/8/1899.

21. Reglamento de Sanidad exterior RD 27/10/1899. El Siglo Médico 1899; 46: 746$50,761-5,779-82,795-8,810-3$ y $828-30$.

22. Malo de Poveda B. El doctor Gimeno, Ministro sanitario. La Medicina Social Española 1919; 4: 33-8.

23. Reglamento de Sanidad exterior. El Siglo Médico 1899; 46: 828-9.

24. Gaceta de Madrid. RO 6/4/1901.

25. Gaceta de Madrid. RO 30/3/1904. GM 28/6/1904.

26. Instrucción General de Sanidad Pública. Edición oficial. Madrid: Tip. Hijos de J. A. García; 1904. p. 52-3.

27. Vila A. Lo que era el Cuerpo de Sanidad Marítima y lo que debe ser el Cuerpo de Sanidad exterior. La Medicina Social Española 1918; 3 : 343-6. p. 344, 345.

28. La Obra Sanitaria en España durante los años 1910 a 1912. Madrid: M $^{\circ}$ de la Gobernación; 1914. p. $9,12,14,123,135$.

29. La Reorganización Sanitaria en España. Madrid: $\mathrm{M}^{\circ}$ de la Gobernación; 1909. p. 37, 41-6, $51,56-60,97,99,118,120,146-8$.

30. Gaceta de Madrid. Preámbulo. RO de 25/2/1909. GM 26/2/1909.

31. Sección oficial. El Siglo Médico 1913; 60: 71.

32. Programa de preguntas para los ejercicios... El Siglo Médico 1887; 34: 718-9, 734-5, 746-7, 766-8 y $813-5$.

33. Gaceta de Madrid. RO 12/1/1911. GM $15 / 1 / 1911$.

34. Gaceta de Madrid. RD 20/1/1911. GM 23/1/1911

35. RO 13/1/1913. El Siglo Médico 1913; 60: 71.

36. Gaceta de Madrid. RO 20/10/1913. GM 23/10/1913.

37. Codina Suqué L, Armiñán A, Codina Suqué J. Manual de legislación sanitaria. Madrid: Gráfica Universal; 1927. p. 392.

38. RO 29/8/1892. El Siglo Médico 1892; 33: 571-2.

39. Gaceta de Madrid. RO 4/7/1893. GM 5/7/1893.

40. Gaceta de Madrid. RD 14/7/1903.
41. Rodríguez Pinilla H. La medicina política en España (Recuerdos de mis días de Inspector sanitario). La Medicina Social Española 1916; 1: 405-10. p. 405.

42. Gaceta de Madrid. RO 30/6/1904. GM 5/7/1904.

43. Gaceta de Madrid. RO 19/10/1904. GM 20/ $10 / 1904$.

44. Gaceta de Madrid. RO 26/1/1905. GM $27 /$ $1 / 1905$.

45. Gaceta de Madrid. RO 13/1/1905. GM 27/ $1 / 1905$

46. Gaceta de Madrid. RO 28/3/1905 GM 29/ $3 / 1905$.

47. Gaceta de Madrid. RO 5/10/1905. GM 8/ $10 / 1905$.

48. Gaceta de Madrid. RO 12/12/1905. GM 22/ $12 / 1905$.

49. García Fraguas JE. Administración Sanitaria Española (Historia y funciones de los Inspectores de Sanidad). Madrid: Administración. de la Revista de Medicina y Cirugía Prácticas; 1907. p. 13, 40-1, 46, 64-6, 71-2, 113.

50. Gaceta de Madrid. Ley 3/1/1907. GM 10/1/ 1907.

51. Gaceta de Madrid. RD 24/2/1908. GM 26/2/ 1908.

52. Gaceta de Madrid. RO 13/4/1908. GM 15/4/ 1908

53. Gaceta de Madrid. RO 3/10/1908. GM 7/10/ 1908.

54. Gaceta de Madrid. Demanda interpuesta por el Inspector de Córdoba. RO 7/8/1908. GM 8/8/ 1908.

55. Gaceta de Madrid. RO 26/10/1908. GM 27/10/ 1908.

56. Gaceta de Madrid. RO 2/1/1912. GM 6/1/1912.

57. Gaceta de Madrid. RO 13/1/1909. GM 14/1/ 1909.

58. Gaceta de Madrid. RO 9/6/1915. GM 10/6/1915.

59. Gaceta de Madrid. RD 29/4/1909. GM 1/5/1909.

60. Gaceta de Madrid. RO 30/6/1904. GM 5/7/1904

61. Gaceta de Madrid. RO de 26/10/19/4. GM $25 / 11 / 1914$

62. Gaceta de Madrid. RD 12/1/1909. GM 13/1/ 1909.

63. Gaceta de Madrid. RD 2/10/1913. GM 7/10/ 1913. 
64. Gaceta de Madrid. RO 8/10/1913. GM 9/10/1913.

65. Gaceta de Madrid. RO 15/6/1912. GM 20/6/ 1912.

66. Gaceta de Madrid. Escalafón del Cuerpo de Inspectores provinciales de Sanidad. RO 31/1/1913. GM 4/2/1913.

67. Gaceta de Madrid. RD 31/5/1916. GM 1/6/1916.

68. Gaceta de Madrid. RD 18/3/1909. GM 20/3/ 1909.

69. Gaceta de Madrid. RD 23/7/1917. GM 28/7/1917.

70. García Durán R. La Asamblca de Inspectores provinciales de Sanidad. La Medicina Social Española 1916; 1: 740-4. p. 741, 744.

71. Asamblea nacional de Inspectores provinciales de Sanidad Celebrada en Madrid del 26 al 30 de noviembre de 1916. Conclusiones aprobadas. La Medicina Social Española 1916; 1: 763-6 y $1917 ; 2: 22-8$ y 59-64.

72. Bercial A. Política sanitaria. La Medicina Social Española 1916; 1: 328-33.

73 La Instrucción General de Sanidad. La Medicina Social Española 1916; 1: 373-9.

74. Sierra y Carbó A. Instituto Nacional de Vacunación. El Siglo Médico 1885; 32: 813-4.

75. RO 24/1/1876. Parte oficial. El Siglo Médico $1876 ; 23 ; 122$.

76. RD 20/11/1885. Sección oficial. El Siglo Médico $1885 ; 32$ : 776-7.

77. Carlán D. Boletín de la Semana. El Siglo Mé dicol 886; 33: 737.

78. Gaceta de Madrid. RD 23/10/1894. GM 24/10/ 1894.

79. Gaceta de Madrid. RO 23/10/1894. GM 25/10/ 1894.

80. Cortezo $\mathrm{CM}^{\mathrm{a}}$. La autonomía sanitaria. Los medios. El siglo Médico 1912; 59: 425-8.

81. Cortezo Collantes VM ${ }^{\mathrm{a}}$. Discurso leído ante la Academia Nacional de Medicina en su recepción pública. Madrid: Bolaños y Aguilar; 1935. p. 38-39.

82. Gaceta de Madrid. RD 27/10/1899. GM 29/10/ 1899.

83. Gaceta de Madrid. RD 2/4/1908. GM 3/4/1908.

84. Instituto Nacional de Higiene de Alfonso XIII. El Siglo Médico 1917; 64: 820 .
85. Gaceta de Madrid. RD 24/1/1911. GM 25/1/ 1911.

86. Gaceta de Madrid. RO 3/10/1916. GM 6/10/ 1916.

87. RD 20/9/1918. Sección oficial. El Siglo Médico 1918; 65: 344.

88. Reglamento de los Sanatorios de Oza (La Coruña) y Pedrosa (Santander). En: La campaña oficial en 1911. Madrid: Publ. de la Comisión Permanente contra la Tuberculosis; 1912. p. 80-94.

89. RD 20/9/1918. Sección oficial. El Siglo Médico 1918; 65: 345.

90. Gaceta de Madrid. RD 31/1/1919. GM 16/2i 1919.

91. Gaceta de Madrid. RO 31/3/1919. GM 8/4/1919.

92. González Alvarez B. Mejora de la población de España. La Medicina Social Española 1919; 4: $249-52$

93. Gaceta de Madrid. RD 9/8/1916. GM 11/8/1916.

94. Gaceta de Madrid. RD 11/2/1919. GM 16/2/ 1919.

95. Rubio de la Torre C. Compendio de Legislación sanitaria. Madrid: Sucesores de Rivadencyra; 1926. p. 21, 24, 27, 37, 39.

96. Cronología. En: Revolución burguesa, oligarquía y constitucionalismo (1834-1923). Barcelona: Labor; 1981. p. 548-9. (Tomo VIII de Historia de España dirigida por Manuel Tuñón de Lara).

97. GM 5 y $7 / 9 / 1919$.

98. Gaceta de Madrid. RD 27/8/1920. GM 10/9/ 1920.

99. Gaceta de Madrid. RO 15/12/1917. GM 16/12/ 1917.

100. Gaceta de Madrid. RO de 16/7/1923. GM 21/7/923.

101. Gaceta de Madrid. RO 14/1/1920. GM 27/1/ 1920.

102. RD 28/2/1922. Sección oficial. El Siglo Médico 1922; 69: 277-8.

103. Malerbe P. La dictadura. En: La crisis del Estado: Dictadura, República, Guerra (19231939). Barcelona: Labor; 1981. p. 37-40 (Tomo IX de Historia de España dirigida por Manuel Tuñón de Lara).

104. Crónicas. El Siglo Médico 1923; 72: 1052. 
105. Proyecto de Ley. El Siglo Médico 1923; 72 : $1176-8$ y $1202-6$.

106. Carlán D. Boletín de la Semana. El Siglo Mé

107. Martínez Cuadrado M. La burguesía conservadora (1874-1931). $7^{\mathbf{a}}$ ed. Madrid: Alianza Ed; 1981. p. 381-6.

108. Gaceta de Madrid. RD 29/9/1923. GM 30/9/ 1923.

109. Carlán D. Boletín de la semana. El Siglo Médico 1923; 77: 1070-1.

110. Palanca JA. Medio siglo al servicio de la Sanidad pública. Madrid: Cultura Clásica y Moderna; 1963. p. 35, 62, 189.

111. Gaceta de Madrid. RD 7/11/1923. GM 9/11/ 1923.

112. Gaceta de Madrid. RO 23/11/1923. GM 1/12/ 1923.

113. RR. DD. 5/12/1923. GM 6/12/1923.

114. Gaceta de Madrid. RD 4/2/1924. GM 7/2/1924.

115. RD 25/2/1924.

116. Esteban García P. La reorganización de los subdelegados de medicina. El Siglo Médico 1928; 81: 466-7. p. 467.

117. Gaceta de Madrid. RO 5/7/1924. GM 8/7/1924.

118. Gaceta de Madrid. RR.OO. 24 y 28/3/1927. GM 25 y 30/3/1927.

119. Perdiguero Gil E, Bernabeu Mestre J, Robles González E. La Salud Pública en el marco de la administración periférica: el Instituto Provincial de Higiene de Alicante (1924-1936). Dynamis 1994; 14: 43-75.

120. Gaceta de Madrid. RD 20/10/1925. GM 24/10/ 1925.

121. Bernabeu Mestre J. El papel de la Escuela Nacional de Sanidad en el desarrollo de la Salud pública en España, 1924-1934. Revista de Sanidad e Higiene Pública 1994; 68: 65-89.

122. Gaceta de Madrid. RD 9/12/1924. GM 12/12/ 1924.

123. Gaceta de Madrid. RO 28/1/1925. GM 1/2/1925.

124. Gaceta de Madrid. RO 30/1/1925. GM 4/2/1925.

125. Saludo. Archivos de Higiene y Sanidad Pública 1925; 1:1.

126. Palanca J. Puntos esenciales para la implantación de la enseñanza sanitaria nacional. Archivos de Higiene y Sanidad Pública 1925; 1: 1824. p. 23.
127. Rico-Avelló C. Notas para la historia de la Sanidad española (folleto para médicos). Madrid: Dirección General de Sanidad; 1955. p. 23.

128. Gaceta de Madrid. RO 12/10/1925. GM 13/11/ 1925.

129. Gaceta de Madrid. RO 26/11/1920.

130. Murillo F. Saludo y programa. Boletín Técnico de la Dirección General de Sanidad 1926; 1: 5-7.

131. Gaceta de Madrid. RO 23/3/1926. GM 26/3/ 1926.

132. Asamblea de Inspectores provinciales de Sanidad. El Siglo Médico 1926; 78: 445-6.

133. Gaceta de Madrid. RO de 15/1/1927. GM 18/ $1 / 1927$.

134. Gaceta de Madrid. RD 29/3/1927. GM 31/ $3 / 1927$.

135. Primera Asamblea de funcionarios de Sanidad Nacional. El Siglo Médico 1927; 80: 484-5 y Primera Asamblea de Sanidad Nacional. Boletín Técnico de la Dirección General de Sanidad 1927; 2: 831-2.

136. Palanca J. Discurso. En: Discursos leídos en la sesión inaugural del año académico de 19271928 de la Sociedad Española de Higiene. Madrid: Imp. Ciudad Lineal; 1927. Citas de p. 27,32 y 37 .

137. Cf. en este mismo número monográfico: Rodríguez Ocaña E. La intervención de la Fundación Rockefeller en la creación de la Sanidad contemporánea en España.

138. Gaceta de Madrid. RO 25/3/1927. GM 27/3/ 1927.

139. Gaceta de Madrid. RD 12/5/1928. GM 13/5/ 1928.

140. Gaceta de Madrid. RO 31/5/1928. GM 1/6/1928.

141. Gaceta de Madrid. RD Ley 20/6/1928. GM 22/ $6 / 1928$.

142. Gaceta de Madrid. RO 16/7/1928. GM 21/7/ 1928.

143. Gaceta de Madrid. Escalafón del Cuerpo de Inspectores provinciales de Sanidad en diciembre de 1927. RO 24/1/1928. GM 10/2/1928.

144. Gaceta de Madrid. RO 3/10/1928. GM 5/10/ 1928.

145. Gaceta de Madrid. RO 6/12/1928. GM 7/12/ 1928. 
146. Gaceta de Madrid. RO 7/12/1928. GM 8/12/ 1928.

147. GM 25/5/1929.

148. Gaceta de Madrid. RO 30/3/1929. GM 2/4/1929.

149. Gaceta de Madrid. RO 5/11/1928. GM 7/11/ 1928.

150. Gaceta de Madrid. RO 31/1/1930. GM 4/2/1930.

151. Gaceta de Madrid. RD 25/2/1930. GM 26/2/ 1930.

152. Gaceta de Madrid. ROC. 1/8/1930. GM 3/8/ 1930.

153. Gaceta de Madrid. RD 8/7/1930. GM 13/7/ 1930.

154. DD. $14 / 4 / 1931$ y $16 / 4 / 1931$. Ministerio de la Gobernación. El Siglo Médico 1931; 87: 439.

155. Gaceta de Madrid. C 29/4/1931. GM 5/5/1931.

156. Gaceta de Madrid. C 19/5/1931. GM 21/5/ 1931.

157. Gaceta de Madrid. O 17/7/1931. GM 18/7/ 1931.

158. Gaceta de Madrid. O 6/8/1931. GM 8/8/1931.

159. D 4/12/1931. Sección oficial. El Siglo Médico 1931; 88: 645.

160. Gaceta de Madrid. O 7/12/1931. GM 8/12/ 1931.

161. Gaceta de Madrid. O 11/4/1932. GM 12/4/1932.

162. Gaceta de Madrid. Ley 14/9/1932. GM 15/9/ 932.

163. Gaceta de Madrid. O 21/9/1932. GM 23/9/ 1932.

164. Gaceta de Madrid. Escalafón del Cuerpo de Sanidad Nacional. 31/12/1934. GM 3/2/1935.

165. Gaceta de Madrid. O 6/2/1933. GM 7/2/1933.

166. Gaceta de Madrid. Ley 11/7/1934. GM 15/7/ 934.

167. Gaceta de Madrid. D 3/9/1933. GM 6/9/1933.

168. Cf. Molero Mesa J. Clase obrera, Medicina y Estado en la España del Siglo XX. Bases sociopolíticas de las campañas antituberculosas entre 1889 y 1950. En: Castellanos J, Jimćncz Luccna I, Ruiz Somavilla $\mathrm{M}^{\mathrm{a} J}$, Gardeta P, editores. La medicina en el siglo XX. Estudios Históricos sobre Medicina, Sociedad y Estado. Málaga: Sociedad Española de Historia de la Medicina; 1998. p. 221-228.
169. Molero Mesa J. Historia social de la tuberculosis en España (1889-1936). Granada, Universidad de Granada [Tesis doctoral en microfichas]; 1989. p. 390-4.

170. Jiménez Lucena I. Cambio político y alternativas sanitarias: el debate sanitario en la II República. Mảlaga, Universidad de Málaga [Tesis doctoral inédita]; 1995. p. 264-76.

171. Gaceta de Madrid. D 25//2/1933. GM 26/12/ 1933.

172. Gaceta de Madrid. D 24/5/1935. GM 25/5/ 1935.

173. Gaceta de Madrid. O 25/5/1935. GM 28/5/ 1935

174. Gaceta de Madrid. Creación del Ministerio de Trabajo, Justicia y Sanidad. D 19/9/1935. GM 20/9/1935 y Corrección GM 1/10/1935.

175. Gacela de Madrid. Reestructuración general de plantillas de la Administración provocada por la Ley de presupuestos de agosto de 1935. D 28/9/1935. GM 29/9/1935.

176. Jiménez Lucena I. El Estado como aliado. Los médicos y el proceso de estatalización de los servicios sanitarios en la Segunda República española. Asclepio 1997; 49: 195-208.

177. Gaceta de Madrid. D 12/10/1935. GM 15/10/ 1935.

178. Gaceta de Madrid. D 4/12/1935. GM 6/12/ 1935 y rectificación GM 1//12/1935.

179. GM 3/2/1935.

180. Rodríguez Ocaña E, Menéndez Navarro A. El Primer Congreso Nacional de Sanidad (Madrid, 1934) como sanción de la profesionalización médico-social en España. Revista de Sanidad e Higiene Pública 1986; 60: 1095107.

181. El Cucrpo de Sanidad Nacional. El Siglo Médico 1933; 92: 672.

182. Cf. Molero Mesa J. Enfermedad y previsión social en España durante el primer franquismo (1936-1951). El frustrado seguro obligatorio contra la tuberculosis. Dynamis 1994; 14: 199225.

183. Fuente Chaos A de la. Política sanitaria. Madrid: Delegación Nacional de Sanidad; 1943. p. 94.

184. Bosch Marín J. Intervención. En: Bermejillo M. Sesión Necrológica en Memoria del 
Excmo. Sr. D. José Alberto Palanca MartínezFortún celebrada en la Real Academia de Medicina el 11 de dicicmbre de 1973. Madrid: RANM; 1973. p. 15-8.

185. Palanca J. Sociología sanitaria y medicina social en España. Discurso correspondiente a la apertura del curso académico 1958-1959. Madrid: Estades; 1958. p. 55 y 116.

186. Boletín Oficial. D 9/11/1939. BO 21/11/1939.

187. Boletín Oficial. O 29/2/1940 BO 16/3/1940.

188. Boletín Oficial. D 9/3/1940 BO 1//3/1940.

189. Boletín Oficial. Convocatoria. BO 13/5/1941.

190. Boletín Oficial. Aspirantes admitidos... BO 19/ $9 / 1941$.
191. Boletín Oficial. O 21/11/1941. BO 13/11/1941.

192. Boletín Oficial. O 22/12/1941. BO 24/12/1941.

193. Conclusiones de la Primera Reunión Anual del Cuerpo Médico de Sanidad Nacional. En: Cuerpo Médico de Sanidad Nacional. Puericultores del Estado. Tisiólogos Españoles (Primeras Reuniones anuales). Conclusiones. Madrid: Dirección General de Sanidad; 1943. p. 9-24.

194. Boletín Oficial. D 30/3/1951. BO 3/6/1951.

195. Bardají López E, Laguna C, Fernández Turégano J, Benítez Franco B. II Reunión Nacional de Sanitarios Españoles. Ponencia General. Perspectivas de la Sanidad en España. Madrid: Imp. Sáez; 1947. 